University of Rhode Island

DigitalCommons@URI

Open Access Dissertations

1978

\title{
A Direct Comparison of Three Fear Assessment Techniques
}

Donald Paul Corriveau

University of Rhode Island

Follow this and additional works at: https://digitalcommons.uri.edu/oa_diss

\section{Recommended Citation}

Corriveau, Donald Paul, "A Direct Comparison of Three Fear Assessment Techniques" (1978). Open Access Dissertations. Paper 934.

https://digitalcommons.uri.edu/oa_diss/934

This Dissertation is brought to you for free and open access by DigitalCommons@URI. It has been accepted for inclusion in Open Access Dissertations by an authorized administrator of DigitalCommons@URI. For more information, please contact digitalcommons-group@uri.edu. 


\section{BESTS \\ F2 \\ C67}

A DIRECT COMPARISON OF THREE FEAR ASSESSMENT

TECHNIQUES

BY

DONAID PAUL CORRIVEAU

A DISSERTATION SUBMITTED IN PARTIAL FULFILLMENT OF THE REQUTREMENTS FOR THE DEGREE OF

DOCTOR OF PHILOSOPHY

IN

PSYCHOLOGY

UNIVERSITY OF RHODE ISIAND

1978

8371907 
ABSTRACT

A review of the literature in avoidance behavior in general and response prevention (RP) in particular revealed that three different assessment procedures have been used to measure Eear. Although the relative advantages and disadvantages of each procedure have been addressed at the conceptual level, they have received little empirical comparison. The present study systematically examined the following assessment procedures: 1) the avoidance extinction technique, 2) the approach procedure, and 3) the conditioned emotional response (CER) procedure. Two different dependent variables were recorded within each assessment procedure. The first purpose of the study was to compare the relative sensitivity of each dependent variable in discriminating the effects of RP. The second purpose was to examine the relationships between these different assessment variables.

Sixty male albino rats were randomly assigned to one of the two treatment groups. After avoidance training, one of these treatment groups received $R P$ and the other group did not. Subjects from each treatment group were then presented all three assessment procedures in one of six possible orders of 
presentation.

Results indicate that both of the approach assessment variables and both of the avoidance assessment variables showed significant RP effects whereas both CER measures Eailed to do so. Results of a discriminant function analysis revealed that approach latency, one of the approach assessment variables, was the most sensitive outcome measure. Surprisingly, the results of a principal component analysis applied to the fear assessment variables found three distinct components. Implications of these results to avoidance theory and research in general as well as to the clinical assessment of avoidance behavior were discussed. 
To my wife Cindy, my son Jeremy and our parents 


\section{ACKNOWLEDGEMENTS}

My initial appreciation goes to my major professor, Nelson Smith, who was primarily responsible for guiding this investigation. His support for this project is overshadowed only by his continuous advice, scholarship and guidance over the five-year span of my graduate education. I am also indebted to the members of my committee, Professors Wayne Velicer, James Prochaska, James Loy and Peter Monti, for their valuable time, effort, and helpful advice. My thanks should be specifically expressed to Wayne for sharpening my methodological skills and for providing generous statistical consultation; to Jim Prochaska whose inspiration has helped insure sufficient breadth in my education; to Jim Loy whose contribution as an "outside member" has been both significant and meaningful; and to Peter, who has been both a colleague and friend for several years. I also wish to thank Sandy Neal for his conscientious assistance in training subjects for this study.

On a more general note, I am grateful to the Providence College psychology faculty for providing a high quality undergraduate education. John Colby in particular was instrumental in shaping many theoretical perspectives and in modeling a sincere appreciation for research. 
I also wish to express sincere appreciation to Jim Curran and Peter Monti for supervising my employment at the V.A. Medical Center. Their advice, encouragement, support and respect have inspired my personal and professional growth in uncounted ways. Their continued concern for my advancement will always be remembered.

I also wish to thank my staff at the Behavior Training Clinic for their continued support. I especially wish to share with them my pride in such a fine crew.

In a more personal sense, I wish to express my fondest gratitude to my parents, relatives and friends for their continuous concern and support. In many ways, they have provided such an important foundation for this degree.

Lastly, my deepest gratitude goes to my wife Cindy. In retrospect, her life as a graduate-student wife required more self-sacrifice than that of her husband. Simple words cannot express my indebtedness for her many contributions. Her patient understanding, unselfish and frequent assistance, unending encouragement and unwavering devotion provided a necessary motivation for this degree. Mostly, her most treasured gift was a fine son. My pride in my accomplishments will never match this gratitude. 


\section{TABIE OF CONTENTS}

PAGE

IIST OF TABIES

vi

INTRODUCTION

METHOD

Subjects

14

Apparatus

Procedure

Operant Training

15

Avoidance Training

15

Fear Assessment

16

Approach Assessment

17

Avoidance Assessment

19

CER Assessment

RESULTS

22

Avoidance Training

22

Univariate Analyses

22

Approach Latency

25

Number of Safety Tests

CER Ratio

CER Latency

Trials to Avoidance Extinction

28

Number of Avoidances

31

Multivariate Analyses

35

Relationships Among the Assessment Variables

39

Further Examination of the Measures

CER Ratios

43

Fear Acquisition and Assessment

44

DISCUSSION

47

REFERENCES

APPINDIX 
1. Outline of the Experimental Design

2. Means and Standard Deviations of the Four Avoidance Training Variables

3. Means and Standard Deviations For Approach Latency

4. Means and Standard Deviations for Number of Safety Tests

5. Means and Standard Deviations for CER Ratio

6. Means and Standard Deviations for CER Iatency

7. Means and Standard Deviations for Trials to Avoidance Extinction

8. Means and Standard Deviations of a Log Transformation Applied to Trials to Avoidance Extinction

9. Means and Standard Deviations for Number of Avoidances

10. Means and Standard Deviations of a Log Transformation Applied to Number of Avoidances

11. Summary of a Direct Solution Method of Discriminant Function Analysis

12. Pearson Correlations Between the Fear Assessment Variables

13. Results of a Principal Component Analysis of the Fear Assessment Variables

14. Results of a Direct Solution of Discriminant Function Analysis for Three Different Sample Durations

15. Correlations Between Avoidance Training And the Fear Assessment Variables 
INTRODUCTION

Avoidance behavior is operationally defined as a learned response which prevents the occurrence of an aversive stimulus. The avoidance response typically requires that an organism escape a warning or conditioned stimulus (CS) which would otherwise terminate in the presentation of an aversive or unconditioned stimulus (UCS). Among several theoretical approaches used to explain the acquisition of avoidance behavior, a dual process explanation appears to be the most popular. One of these, Mowrer's two-factor theory, postulates that there are two components or processes thought to be involved in the learning of avoidance behavior. The first factor involves a classically conditioned fear response acquired by pairing a previously neutral stimulus with a primary noxious or aversive stimulus. The second component consists of the instrumental reinforcement of the avoidance response via fear reduction. As seen in the animal analogue paradigm, the animal first learns to fear a stimulus and whatever the animal does to terminate that stimulus is operantly reinforced.

Early research into animal avoidance learning 
page 2

(i.e. Solomon \& Wynne, 1954) showed avoidance behavior remarkably resistant to extinction. In the laboratory the classical extinction procedure is to discontinue the presentation of shock while css continue to be presented. Since shock is not presented during avoidance responses las is found in latter segments of avoidance training), the extinction procedure does not introduce a discriminable change. In essence, the animal has learned to avoid the very situation where relearning could take place. A similar process has been attributed to human neurotic behavior which is also characterized by its self-defeating and self-perpetuating nature (Mowrer, 1950).

The proliferation of interests in methods of eliminating avoidance behavior is best attributed to both the apparent similarity of avoidance behavior in animals and anxiety-motivated phobic behavior in humans (Bandura, 1969; Baum \& Poser, 1971) as well as to the empirical evidence that both animal and human avoidance behavior is highly resistant to extinction (Baum, 1965; Hodgson \& Rachman, 1970; Levis, 1966, 1970, 1974; Solomon \& Wynne, 1954).

Among several techniques used to eliminate 
page 3

avoidance responses in animals, the most popular appears to be a technique originally called "Forced Reality Testing" (Solomon, Kamin \& Wynne, 1953) and presently called "Response Prevention" (Baum, 1970). The technique has been extended to clinical applications under the names of Implosive Therapy, Flooding, and Response Prevention (Ayer, 1972; Baum \& Poser, 1971; Hodgson \& Rachman, 1970; Hogan, 1968, 1969; Levis, 1966, 1970, 1974; Morganstern, 1973, 1974; Rachman, 1968; Smith, Dickson \& Sheppard, 1973; Stampfl, 1966; Stampfl \& Levis, 1967, 1968; Staú, 1958).

Response Prevention (RP) consists of preventing the avoidance response in the presence of the feared CS. The conditioned fear response is then postulated to be classically extinguished because the $c s$ is being presented without being paired with the UCS. Baum (1966), for example, trained rats to jump to a platform locatej 6 in. above a grid floor to avoid shock. When the learning criteria of 10 consecutive avoidance responses was attained, a group of subjects received a RP procedure. The conditioned avoidance response (CAR) was blocked by retracting the platform making it unavailable for an avoidance response. The results of 
page 4

this and other studies revealed that RP significantly facilitated the subsequent extinction of the CAR (Baum, 1959a, 1970; Baum \& Higgins, 1971; Berman \& Katsev, 1972; Coulter, Riccio \& Page, 1969; Linton, Riccio, Rohrbaugh \& Page, 1970; Marrazo, Riccio and Riley, 1974; Page, 1955; Page and Hall, 1953; Reynierse \& Wiff, 1973; Schiff, Smith \& Prochaska, 1972; Siegeltuch \& Baum, 1971; Voss, Mejtal and Reid, 1974).

Both theoretial and applied interest in RP generated an expansive literature of parametric investigations. Among the factors investigated were ucs intensity (Baum, 1969a, Corriveau, 1977), RP duration (Baum, 1959a, 1969b), overtraining (Baum, 1968), massed vs. distributed RP (Berman \& Katsev, 1972; Schiff, Smith \& Prochaska, 1972; Tortora \& Denny, 1973) and several supplementary techniques which increased the efficiency of RP (Baum,1969,1972; Baum \& Gordon, 1970; Gordon \& Bauin, 1971; Lederhendler \& Baun, 1970; Reynierse \& Straw, 1974).

As is quite typical of major research areas, the RP literature is not devoid of both empirical and conceptual problems. A notable and persistent issue revolves around the fear construct. First, on purely 
page 5

theoretical grounds, the covert nature of the fear construct has proved offensive to operant theorists (e.g. Herrnstein, 1969; Herrnstein \& Hineline, 1966). Although a purely operant interpretation has been applied to both discriminated and nondiscriminated avoidance training procedures, an operant analysis appears incapable of explaining acquired drive properties (Bolles, 1975a, 1975b). Although most avoidance theorists would agree that the fear construct need be retained, it remains crucially unclear how best to measure fear. This empirical question remains unresolved and is perhaps the most central issue in avoidance research in general and $R P$ research in particular.

Historically, reduction in the CAR was postulated to reflect reduction in fear. The fear construct was quantified by observing avoidance persistence. To date, a vast majority of RP research employs reduction of avoidance behavior during extinction as the major (and in most cases the only) dependent variable. Typically. researchers record either the number of trials it took for subjects to reach an extinction criterion (e.g. five non-avoidance trials) or the number of avoidance trials 
page 6

emitted during a predeterminad number of extinction trials. A perusal of this literature suggests that the former dependent variable, trials to extinction criteria, is most frequently used. Essentially, a RP procedure is either presented or not presented following avoidance training and subsequent reduction in zvoidance behavior is examined. Unfortunately, this methodology contains a potential confound: RP consists of a physical procedure plus a duration of elapsed time between training and testing whereas Non-Response prevention usually consisted of an absence of both the physical procedure and the elapsed time between training and testing. It is indeed unfortunate that several studies have not controlled elapsed time (Baum, 1965, 1969a; Baun \& Higgins, 1971; Lederhendler \& Baum, 1970; Linton, Riccio, Rohrbaugh \& Page, 1970; Marrazo, Riccio \& Riley, 1974; Page, 1955; Page \& Hall, 1953; Siegeltuch \& Baum, 1971).

A second methodology found in the literature is called the approach latency method and was first advanced by the "competing-response" theorists (e.g. Page, 1955). Competing response theorists argue that RP serves to instrumentally condition a new response le.g. 
page 7

freezing) which is reinforced by the absence of shock. Consequently, they contend that using reduction in the CAR as an assessment procedure can lead to artifactual findings. Page (1955) in his early research found that although reduction of the CAR had been facilitated by blocking the response, latencies for approaching the avoidance chamber for food were significantly longer for blocked than nonblocked subjects. Hence, Page concluded that blocked animals were more fearful than animals extinguished in a normal fashion. His conclusions were somewhat premature, however, in that his study also had several methodological difficulties. Most notable of these problems was that his approach latency measure followed (by 24 hours) extensive extinction trials and consequently blocked subjects received less total cs exposure than the nonblocked controls. However, similar studies (Coulter, Riccio \& Page, 1969; Linton, Riccio, Rohrbaugh \& Page, 1970) have found results consistent with Page (1955), although blocked subjects were typically less Eearful than a nonblocked group which did not receive previous extinction trials (cf. Riccio s Silvestri, 1973). Hence, it appears that the avoidance assessment procedure is suspect to a competing response 
page

interpretation.

It should be emphasized that the competing response interpretation does not discount the ability of $R P$ to reduce fear. Rather, it firmly maintains that reduction in avoidance behavior can be due to either fear reduction or reinforced competing responses. In the latter case, fear would not be assumed to be reduced. Given the potential confound inherent in the avoidance assessment procedure, it is surprising that the approach latency procedure, which is free from competing response interpretations, has not received more attention and employment.

Aside from the use of avoidance or approach methodologies to assess fear, a third procedure is found in the RP literature. Monti \& Smith (1976), for example, used the conditioned emotional response (CER) paradigm, which consists of the presentation of a formerly avoided CS (e.g. tone) during the course of ongoing operant behavior (e.g. bar-pressing). An index of fear is derived from the suppression of the instrumental behavior during the presentation of the CS. Greater suppression is assumed to be reflective of greater fear. The results of Monti and Smith's study 
page 9

showed that RP was effective in reducing fear, although complete fear reduction was not found. This major finding, clearly aiscrepant with previous RP research, suggested that earlier studies examining RP did not reveal residual fear because the avoidance assessment procedures employed to assess fear were not sufficiently sensitive. These results were corroborated by corriveau \& Smith (1978) who improved on the approach assessment methodology and found that a protracted duration of RP led to substantial yet incomplete fear reduction.

Although the conceptual advantages and disadvantages of the three fear assessment methodologies have been discussed (Corriveau \& Smith, 1978; Corriveau, Contildes \& Smith, 1978; Monti \& Smith, 1976; Testa, 1976), they have received extremely limited empirical comparison. The studies by the competing response theorists cited above completely neglected to present any correlational data between the avoidance and approach methodologies. Moreover, even if these original data could be found, their procedures did not control for sequence presentations. One study by Kamin, Brimer \& Black (1963) examined the relationship between the CER and the acquisition of avoidance behavior. 


$$
\text { page } 10
$$

Briefly, the first experiment of that study compared CER ratios of subjects who met extinction criteria of either 0,5 , or 29 nonavoidance trials. Results of this experiment showed that fear of the Cs, as measured by CER suppression ratios, decreased as subjects received prolonged extinction trials. Unfortunately, the design of their study did not examine the degree of relationship between avoidance and CER measures. Their data simply suggests that prolonged extinction trials result in reduced fear, as measured by the CER assessment procedure.

Another study by Bankart and Elliott (1974) employed a CER suppression index as one dependent variable and an avoidance extinction variable as its second outcome measure. Their results showed significant RP effects with the avoidance assessment procedure but not with the CER procedure. Moreover, their results failed to show a significant correlation between these two variables.

One other approximation to an empirical examination of the various assessment procedures is Found in the study by corriveau s Smith (1978). They primarily employed an approzch assessment procedure 
page 11

which recorded subjects' latencies to completely depart a platform and approach a grid floor. However, they also recorded an avoidance latency score which was simply the amount of time subjects stayed on the grias before avoiding them and returning to the platform. This latter dependent variable was conceived as indicative of avoidance behavior. The results of their study showed that avoidance latency was only moderately correlated with approach 1atency ( $r=-.26)$. Moreover, avoidance latency appeared to be a less sensitive measure: The approach latency data showed that RP subjects were less fearful than non-response prevented subjects but more fearful than non-avoidance trained control subjects, whereas the avoidance latency data failed to reveal a significant difference between control and RP subjects.

In essence, the dearth of empirical comparisons between the various fear assessment procedures remains one of the most problematic features of the RP 1iterature. Indeed, this central issue poses several crucial questions. Are the results of different methodologies comparable? Are they even measuring the same construct? Assuming that they are all measuring 
- ar. are they equaliv sensitire or power Eul?

This study proposes to emplrically examine and compare the tnree fear assessing nethodologies. The study inciuied groups of subjects who elin-t received or dia not $r e s e i v \geq$ R. Ali subjects assessment procajures (avoialang, aporoada ana SER) in various orjars of presentation. The first purpose of the study was to examine the aifferential power of these fear assessmant matnodologies in disariminating RP subjects from tnose that dia not rezeive response prevantion (NRP). A saconj purpose was to exanine the relationships among tho dependent variables.

Since the various assessment procedures examine typographically aifferent behaviors, an examination of the relationships among the dependent variables is arucial to a betear understaning of botr aroidanae acquisition and responso preyention. Similarly, tine plethora of paranatric invastigations in RP attests to tne importanse of examining cne differencial sensitivities of the various dependent variables. Unless this information is obtainad, a comparison between stuaies using aifferent metrodologies is at best in adequate. 
$239=13$

betwean studies using differant nathodologies is at best in adequate. 
page 14

METHOD

\section{Subjects}

The subjects were 65 experimentally naive Sprague Dawley male rats obtained from the charles River Breeding Laboratory. They were maintained on ad libitum food and water until their use in the study, at which time they averaged $338.5 \mathrm{gm} .(S D=53.7)$. Two subjects were discarded for failure to meet avoidance training criteria and three were replaced due to equipment Eailure.

\section{Apparatus}

Equipment consisted of a one-way platform avoidance apparatus, model 85200, manufactured by the Lafayette Instrument Company. The grid chamber was 23 $\mathrm{cm}$. long, $20.3 \mathrm{~cm}$. wide and $20.3 \mathrm{~cm}$. high. The entire apparatus was housed in a sound attenuated chamber. Operant training and CER assessment was done in standard lever boxes (modified to record licking behavior) also contained in sound attentuated chambers. A wooden retaining chamber was constructed of equal dimensions to the avoidance apparatus shock-chamber. All procedures except placing and removing the subjects from the 
apparatus was automated with standard electro-mechanical programming equipment.

\section{Procedure}

\section{Operant Training}

All subjects were housed individually and deprivad of water for $48^{\circ}$ consecutive hours prior to their use in the experiment. Licking behavior for water reinforcement was then shaped to a VR ID schedule during a 30 min. training session. subjects received two additional training sessions on consecutive days. All subjects showed stable performance in the third daily session.

Subjects were generally not given water other than that received during training unless their body weight fell below 80 percent of their pretraining weight, in which case they received $10-20 \mathrm{~min}$. Eree water in their home cage. The average weight throughout training was $.87 \%(S D=.07)$.

\section{Avoidance Training and Response Prevention}

All subjects were trained to a criterion of 10 consecutive avoidance responses. Subjects not meeting 
page 16

this criterion within 60 trials were discarded and replaced. An avoidance response was defined as jumping completely up to the platform within a 10 sec. cs-ucs interval and remaining there for $15 \mathrm{sec}$. The cs was a $85 \mathrm{~dB}$ (A) white noise and the UCS was a 1.5 milliamp scrambled snock. A variable $30 \mathrm{sec}$. intertrial interval was used. Subjects receiving response prevention remained in the avoidance apparatus for $45 \mathrm{~min}$. following their loth consecutive response. These subjects were then placed in the retaining cage for 1 min. Subjects not receiving response prevention were placed in the retaining cage immediately after their loth consecutive avoidance response for $46 \mathrm{~min}$. It should be noted that the RP procedure did not present the white noise CS. This was done to circumvent the problem of selecting cS presentation frequencies (see discussion).

Four dependent variables which were thought to reflect the acquisition of avoidance behavior were recorded. They were: 1) Number of trials to avoidance training, 2) Number of shocked trials, 3) Total number of shocks, and 4) Total uCs duration.

Fear assessment

Immediately following avoidance training and 
page 17

response prevention, all subjects received all three fear assessment procedures. Subjects were assigned to one of six possible sequences of these assessment procedures. Thus, five subjects from each treatment group (RP or NRP) were assigned to a particular sequence group. The design of the study is shown in Table 1. Each assessment procedure had a $30 \mathrm{~min}$. duration. If a particular assessment procedure was completed before 30 min., the subject was placed in the wooden retaining cage for the remaindar of the procedure. If the assessment procedure was not completed before $30 \mathrm{~min}$. the subject was placed in the wooden retaining cage for 1 min. and received a "ceiling" score, described below. Thus, each assessment procedure was initiated at regular 30. min. intervals. The different procedures for each type of assessment were as follows:

Approach assessment. Subjects were placed on the platform of the avoidance apparatus. Only $21 / 2$ in. of the platform was available to the subjects for this part of the study. Two dependent variables were recorded during this procedure. The first, approach latency, was defined as the time it took for subjects to completely depart the platform and remain on the grids for at least $3 \mathrm{sec}$. If a subject did not depart the 


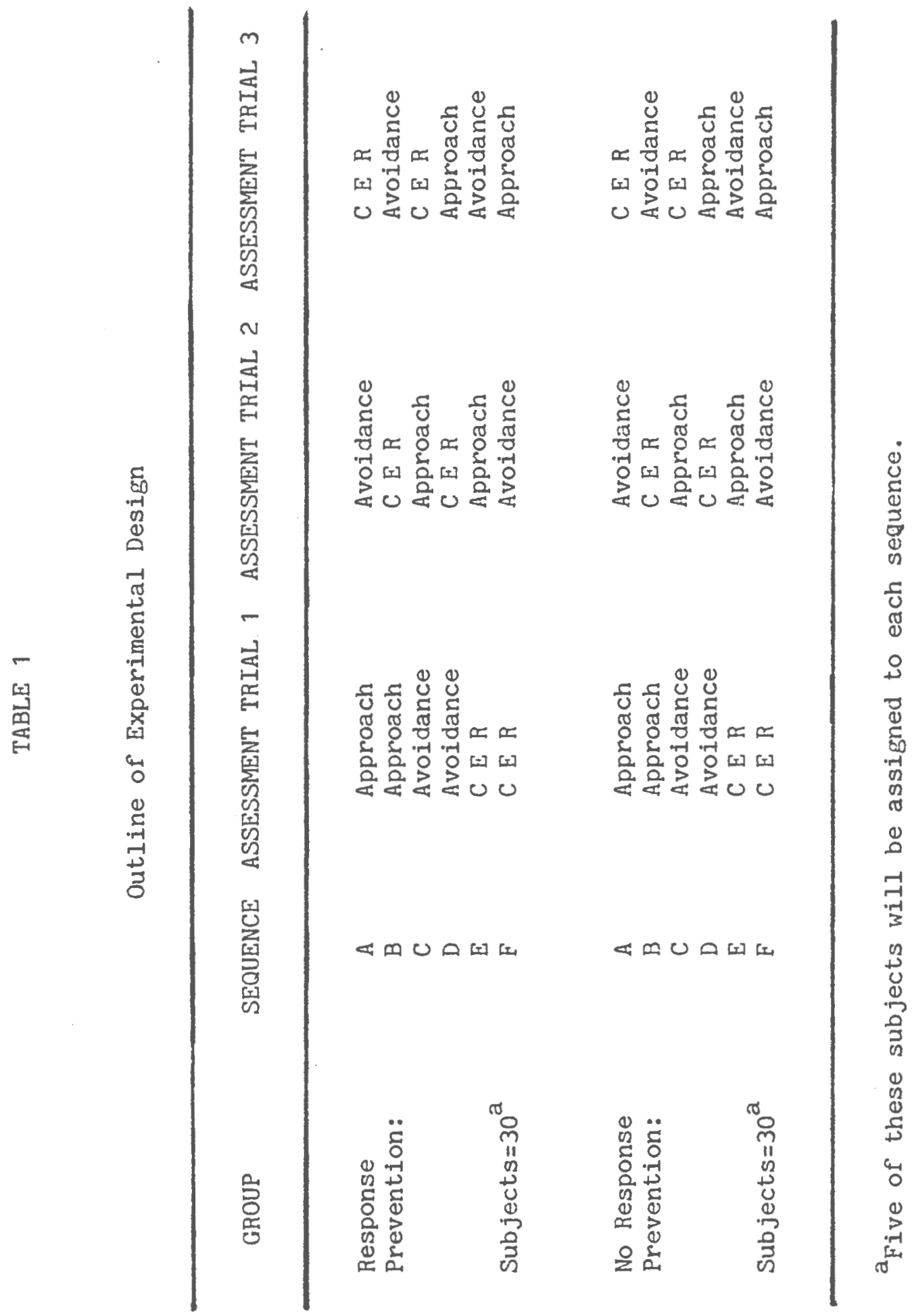


platform within 30 min., a "ceiling" score of $180 \mathrm{~g}$ sec. was recorded. The second dependent variable, number of safety-tests, was simply the number of times the subjects touched the grias with their paws before a complete approach response was made. The typography and nature of safety-test behavior was initially reported by Corriveau \& Smith (1978). After completion of this assessment procedure, subjects were returned to the retaining cage.

Avoidance assessment. The avoidance assessment procedure was identical to avoidance training except that shock was not presented. If a subject did not avoid within 10 sec., the cs was discontinued and the trial was terminated. These trials continued until subjects failed to avoid on three consecutive trials.

Two dependent variables were recorded during this assessment procedure. Trials to avoidance extinction, was simply the number of trials required for a subject to reach criterion of three consecutive non-avoidances. Number of avoidances was the number of avoidance responses emitted before extinction criteria. After completion of this assessment procedure, subjects were returned to the retaining sage.

CER assessment. Subjects were initially placed in 
page 20

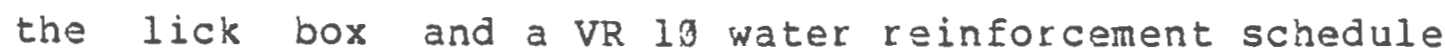
was initiated. To control for satiation, the CER assessment began immediately following the $50 \mathrm{th}$

reinforcement. Here again, two dependent variables were recorded. The first, CER ratio, was computed by recording the number of lick responses emitted during two consecutive $30 \mathrm{sec}$. intervals. The first interval was used to assess free operant frequency rates. The CS probe, an $85 \mathrm{~dB}$ white noise, was presented continuously during the second $30 \mathrm{sec}$. interval. The CER suppression ratio was computed as follows: Responses before CS divided by the sum of responses before and during the CS $(C E R$ ratio $=A / A+B)$. Using this formula, a ratio of 1. 0 represents complete suppression, while a ratio of .5 represents a complete lack of suppression.

It should be added that. Erequency rates were actually recorded within 19 sec. samples. Three consecutive $10 \mathrm{sec}$. samples were used as the pre-cs interval and three consecutive 10 sec. samples were recorded during the CS probe. As will be discussed later, this was done to compare the efficiency of 10 sec., 20 sec., ana 30 sec. CER ratios.

The second dependent variable recorded during this assessment procedure was called CER latency. This 
page 21

variable consisted of the time following the onset of the cs probe it took for subjects to emit Io licks. IE a subject did not emit 10 licks during the cs probe, a "ceiling" score of 30 sec. was recorded. After completion of this assessment procedure, subjects were returned to the retaining chamber. 
RESULTS

\section{Avoidance Training}

Initial analyses examined whether RP and NRP groups received equivalent avoidance training. Table 2 shows the means and standard deviations for the following four variables recorded during avoidance training: trials to avoidance acquisition, number of shocked trials, total number of shocks and total Ucs duration. Individual $t$ tests applied to these variables, also presented in Table 2, were all nonsignificant, indicating that both groups of subjects received equivalent avoidance training.

\section{Univariate Analyses}

This section describes a series of univariate analyses of variance performed to compare the ability of each dependent variable to differentiate the effects of RP. These analyses were also designed to examine a potential confound of the study.

It should be noted that this study compared three procedures purported to assess fear. It is conceivable that the presentation of an assessment procedure may 
page 23

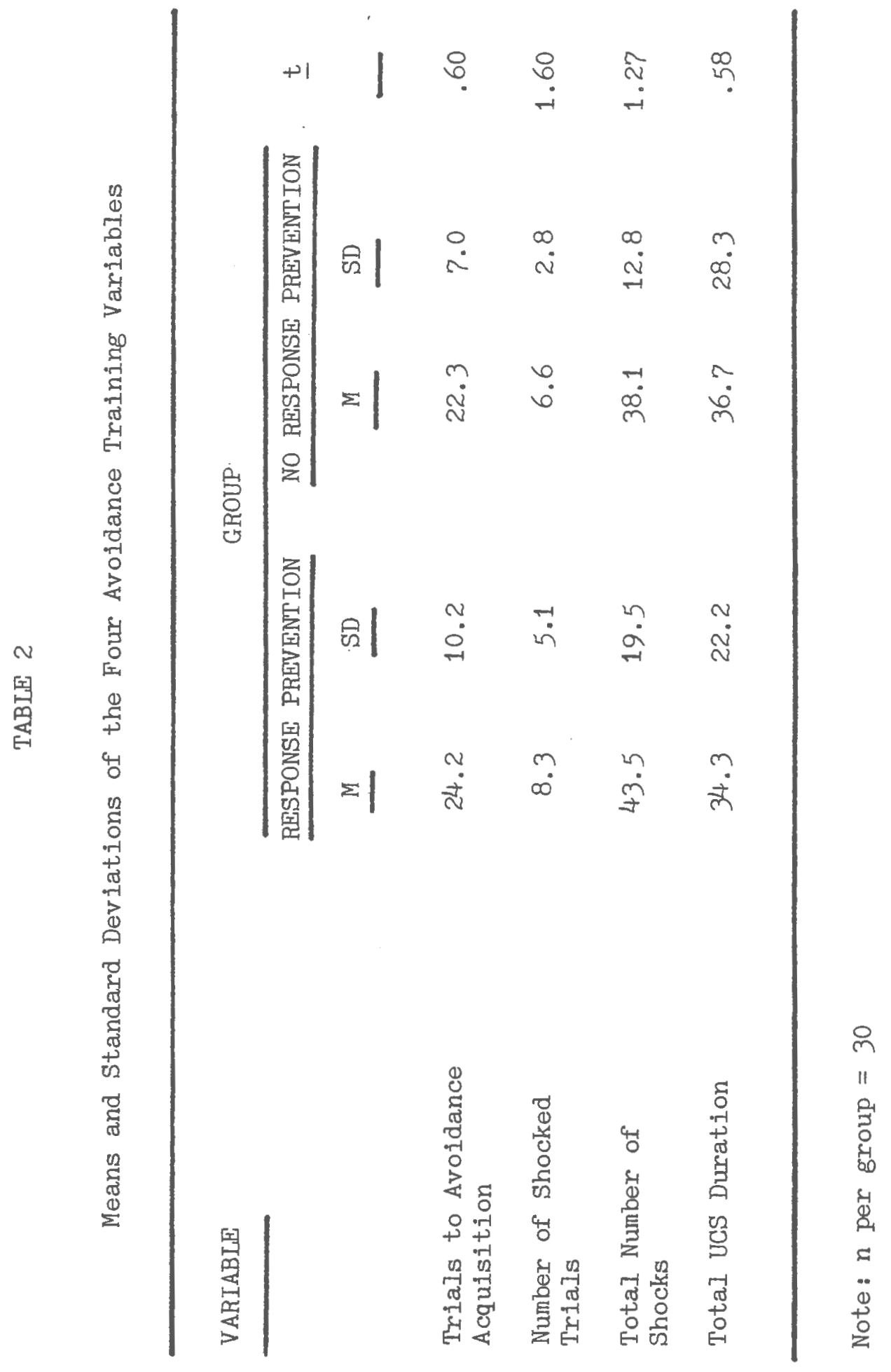


itself reduce fear. This potential reactivity of measurement would be especially problematic if a particular assessment procedure led to major fear reduction. Consider, for example, the problem which would arise if the approach assessment procedure itself led to complete fear reduction. The CER and avoidance data obtained from subjects who received these procedures after the approach procedure would not be sensitive compared to the data obtained from subjects receiving the CER and avoidance procedures before the approach procedure. Hence, the following analyses compared all animals that received a particular assessment procedure on trial 1 vs. those animals that received the procedure on trial 2 vs. those subjects receiving the assessment procedure on trial 3. Thus, this section will report a series of 2 by 3 analyses of variance. In all cases, these analyses will be preceded by $F$ max tests to test for the assumption of homogenaity of variance. Since the analysis of variance is relatively insensitive to this assumption, an alpha level of .01 was selected for these $F$ max analyses. (since one of the cells had zero variance for the 
avoidance data, the variance for this cell was assumed to be .Dl for the $F$ max analyses.)

\section{Approach Assessment: Approach Latency. Table 3} shows the means and standard deviations for approach latency for both treatment and assessment trial groups. This table suggests that subjects receiving RP approached the grid floor sooner than NRP subjects. An $F \max$ test was nonsignificant $(F \max =5.5)$. An analysis of variance (Appendix A) performed on these data revealed a significant treatment effect, $F(1,54)=$ 20.9; $\mathbf{Q}<.001$, with no significant trial effect, $F$ $(2,54)=1.2 ; \mathrm{p}>.05 ;$ or interaction effect, $F<1.0$.

Approach Assessment: Number of Safety Tests. Table 4 shows the means and standard deviations of number of safety tests for both treatment groups across all assessment trials. These means suggest that the NRP group engaged in more safety-test behavior before approaching the grids. The table also suggests that the NRP group receiving the approach procedure first emitted the most safety tests. An F max test was nonsignificant (F $\max =9.7)$. An analysis of variance (Appendix B) applied to these data showed a significant treatment 
page 26

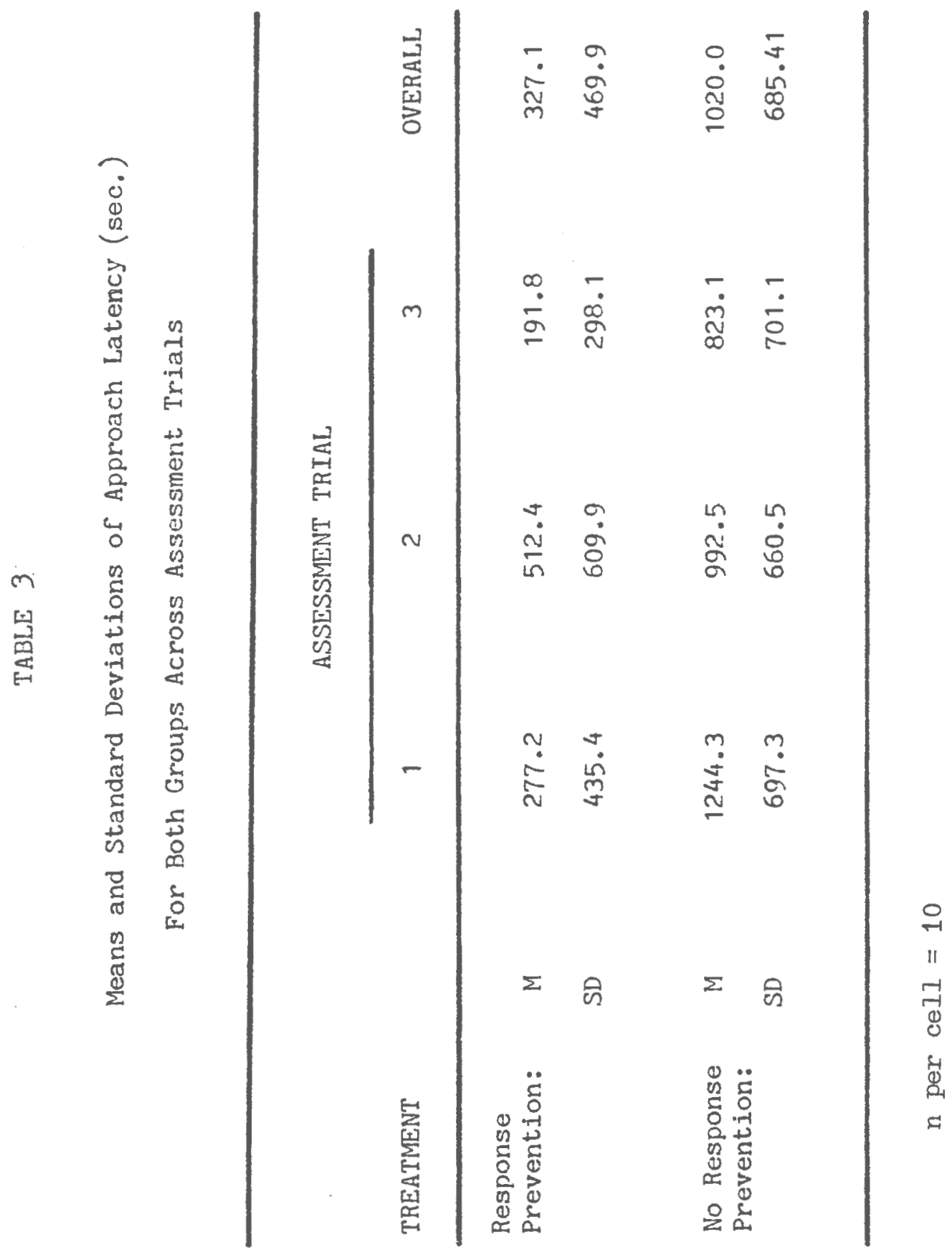


page 27

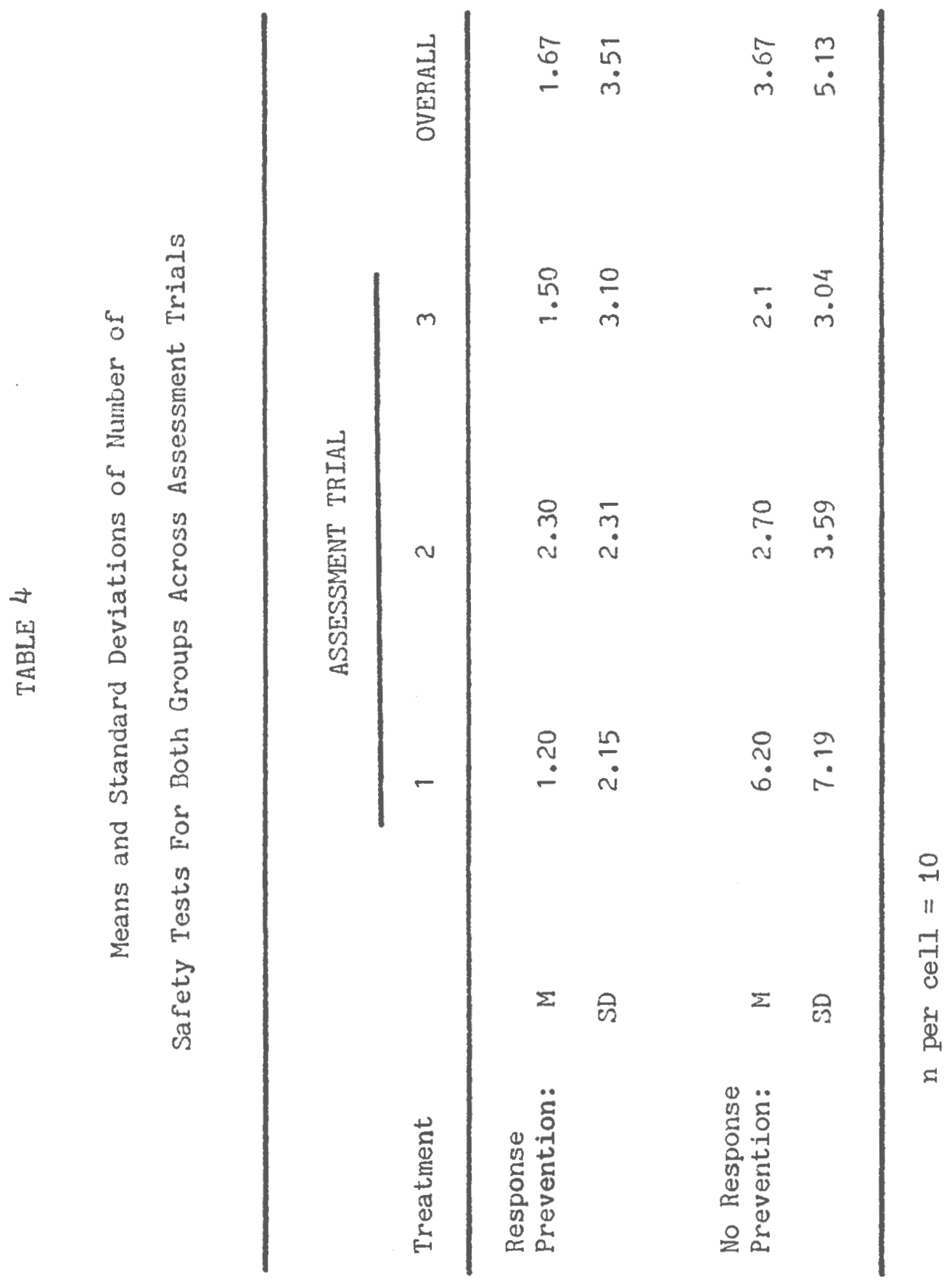


effect, $F(1,54)=3.9 ; \mathrm{Q}<.05$, but no assessment trial, $F(2,54)=1.2 ; \underline{P}>.05$, or interaction $(F<1.0)$ effect.

CER Assessment: CER Ratio. Table 5 shows the means and stanảard deviations for CER ratio across treatment groups and assessment trials. An $F$ max test was nonsignificant $(F \max =1.2)$. These ratios appear very similar across all groups. Indeed, an analysis of variance (Appendix C) applied to these data revealed no significant treatment, assessment trial or interaction effect (all F's $<1.0$ ).

CER Assessment: CER Latency. Table 6 shows the time in sec. it took for subjects to emit 10 licks. These means and standard deviations are presented for both treatment groups across all assessment trials. An $F \max$ test was nonsignificant $(F \max =1.5)$. These CER data also fail to suggest any group differences. In fact, the RP group generally appeared to take slightly longer than the NRP group. The results of an analysis of variance (Appendix D) on these data did not reveal any significant main or interaction effect lall F's< $1.0)$. 


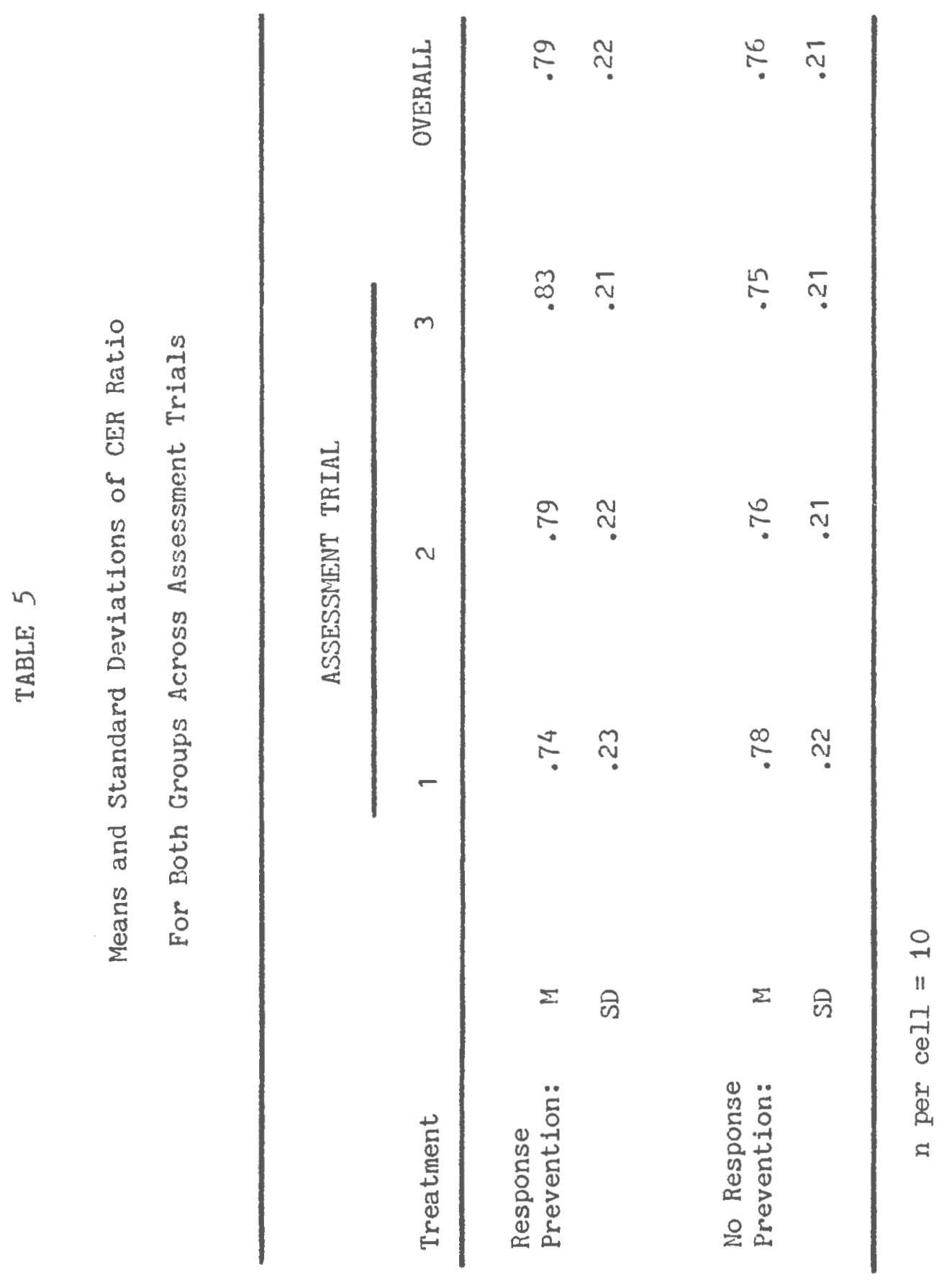


page 30

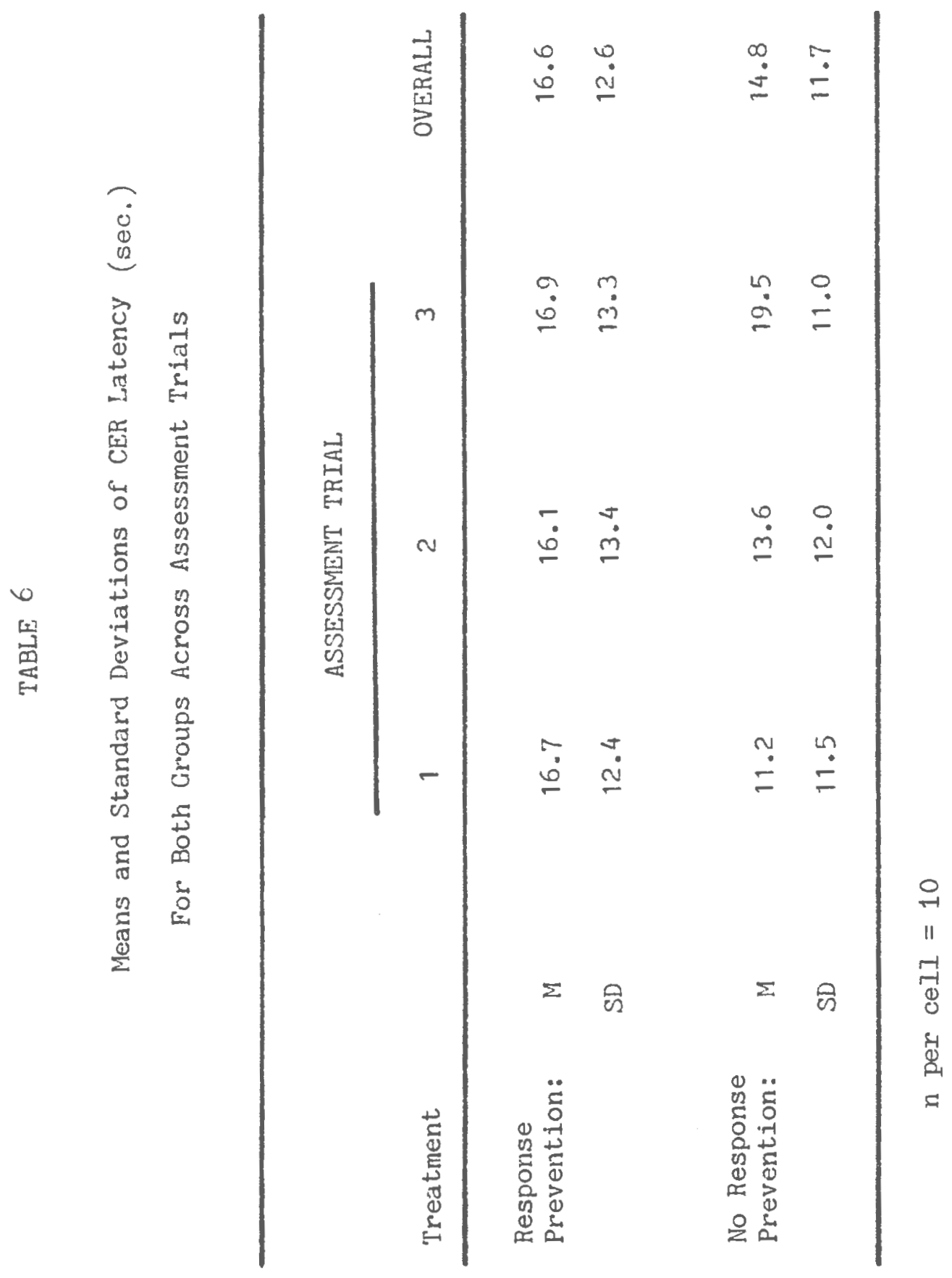


page 31

Avoidance Assessment: Trials to Avoidance

Extinction. The means and standard deviations for trials to avoidance extinction for both treatment groups and assessment trials are presented in Table 7. This table suggests that the NRP group required more extinction trials to reach criteria. These data merit closer inspection in that the cell variances appear seriously heterogeneous. Although the analysis of variance is relatively insensitive to violations of the assumption of homogenous variance, the degree of heterogeneity in these data was considerable $(\mathrm{F} \max =$ 889.2). A common log transformation (base 10) applied to these data removed this heterogeneity ( $\max =1.2)$. The means and standard deviations for this transformed scale are shown in Table 8. An analysis of variance (Appendix E) applied to this transformed scale revealed a significant treatment effect, $F(1,54)=4.79 ; \mathrm{Q}<$ .05, with no trial or interaction effect (F's $<1.0)$.

Avoidance Assessment: Number of Avoidances. The means and standard deviations for number of avoidances are shown in Table 9. These data possessed the same problem with heterogeneity of variance, $(F \max =665.9)$. 
page 32

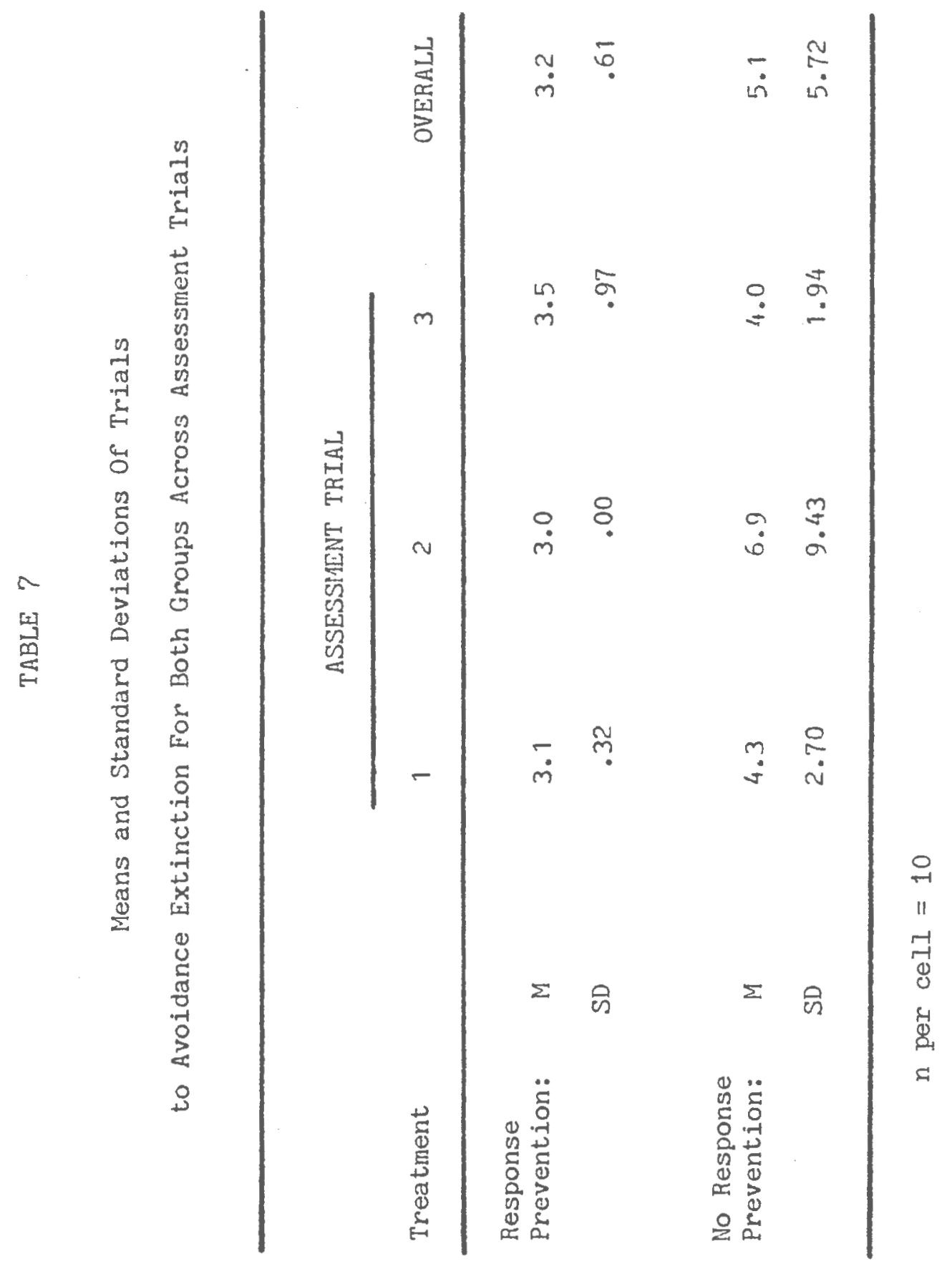




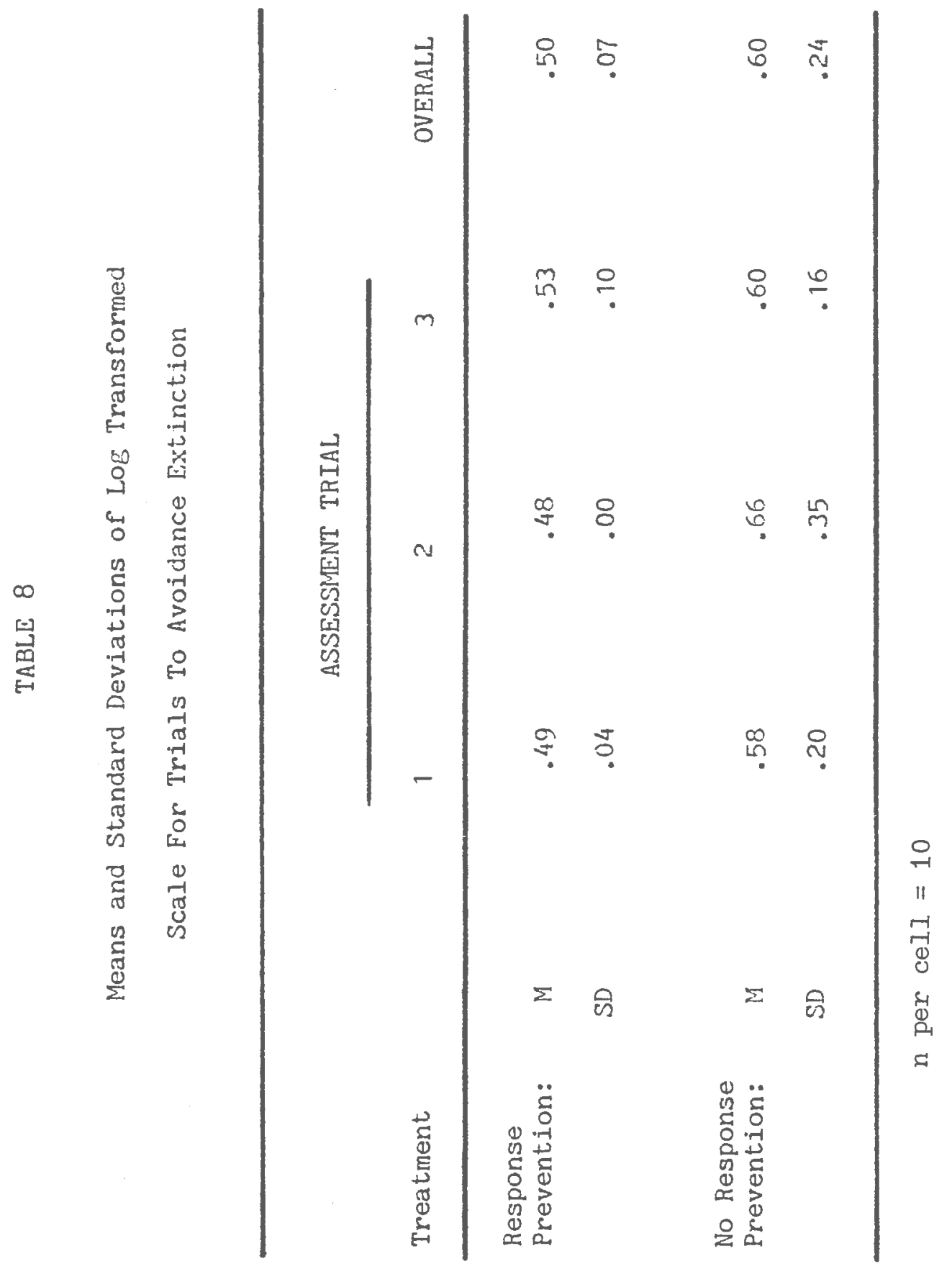




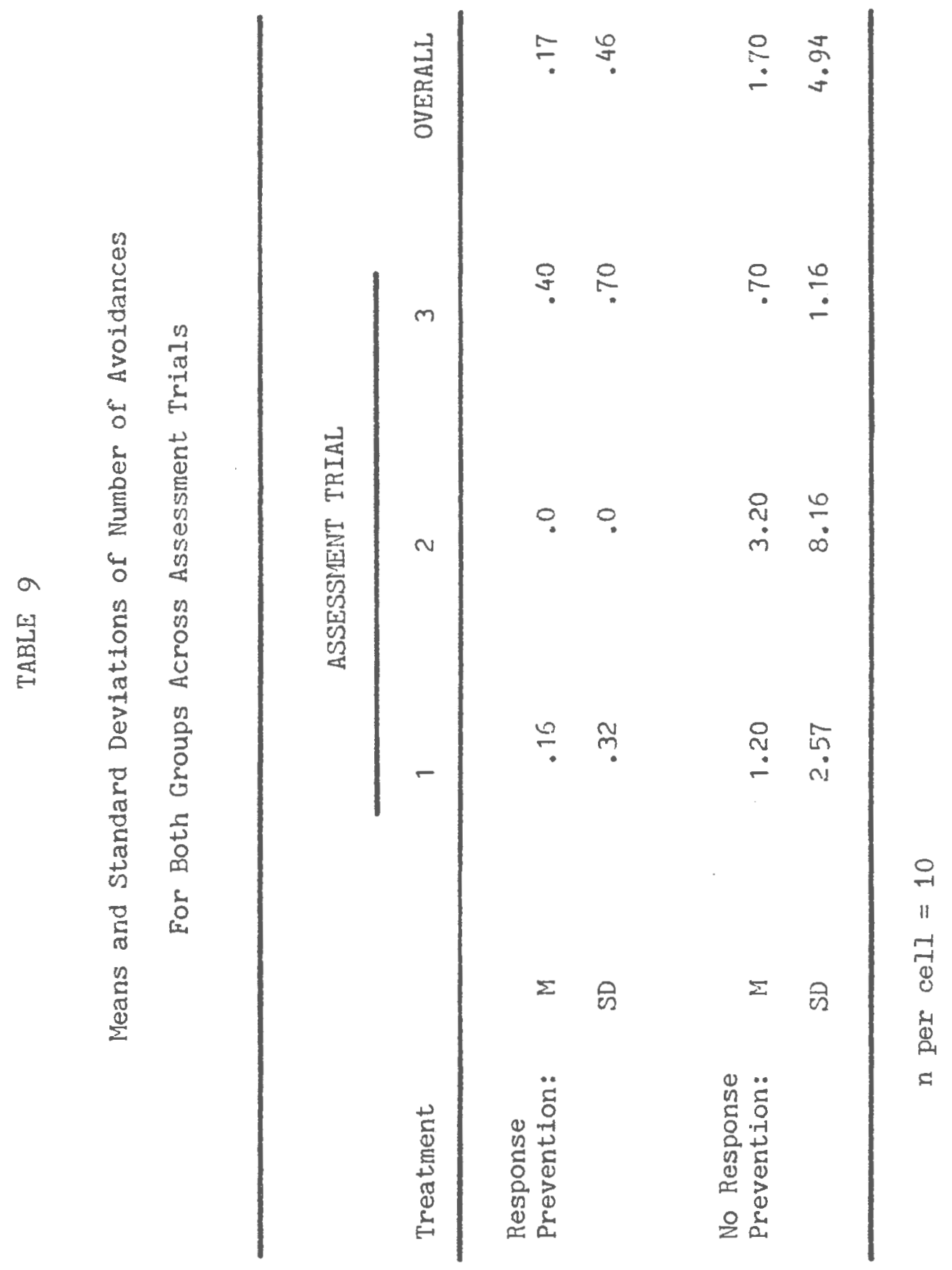


A log transformation of these data was subsequently performed and the transformed variable failed to be significantly heterogeneous $(F \max =2.3)$. The means and standard deviations for this transformed scale are shown in Table 10. An analysis of variance (Appendix F) applied to these data revealed a significant treatment effect, $F(1,54)=5.02 ; \underline{p}<.05$, but no significant trial $(F<1.0)$ or interaction effect, $F(2,54)=2.37$; p > .85.

In summary, both approach and both avoidance measures revealed a significant difference between RP and NRP groups. Both CER measures showed nonsignificant treatment effects. For all variables, assessment trial and interaction effects were nonsignificant, indicating that reactivity of measurement was not demonstrated in the present study. (An alternative test for reactivity could have been made by comparing the six different sequence groups across treatment groups. These results found in Appendix $G$ also failed to demonstrate any significant sequence or interaction effect.) 
page 36

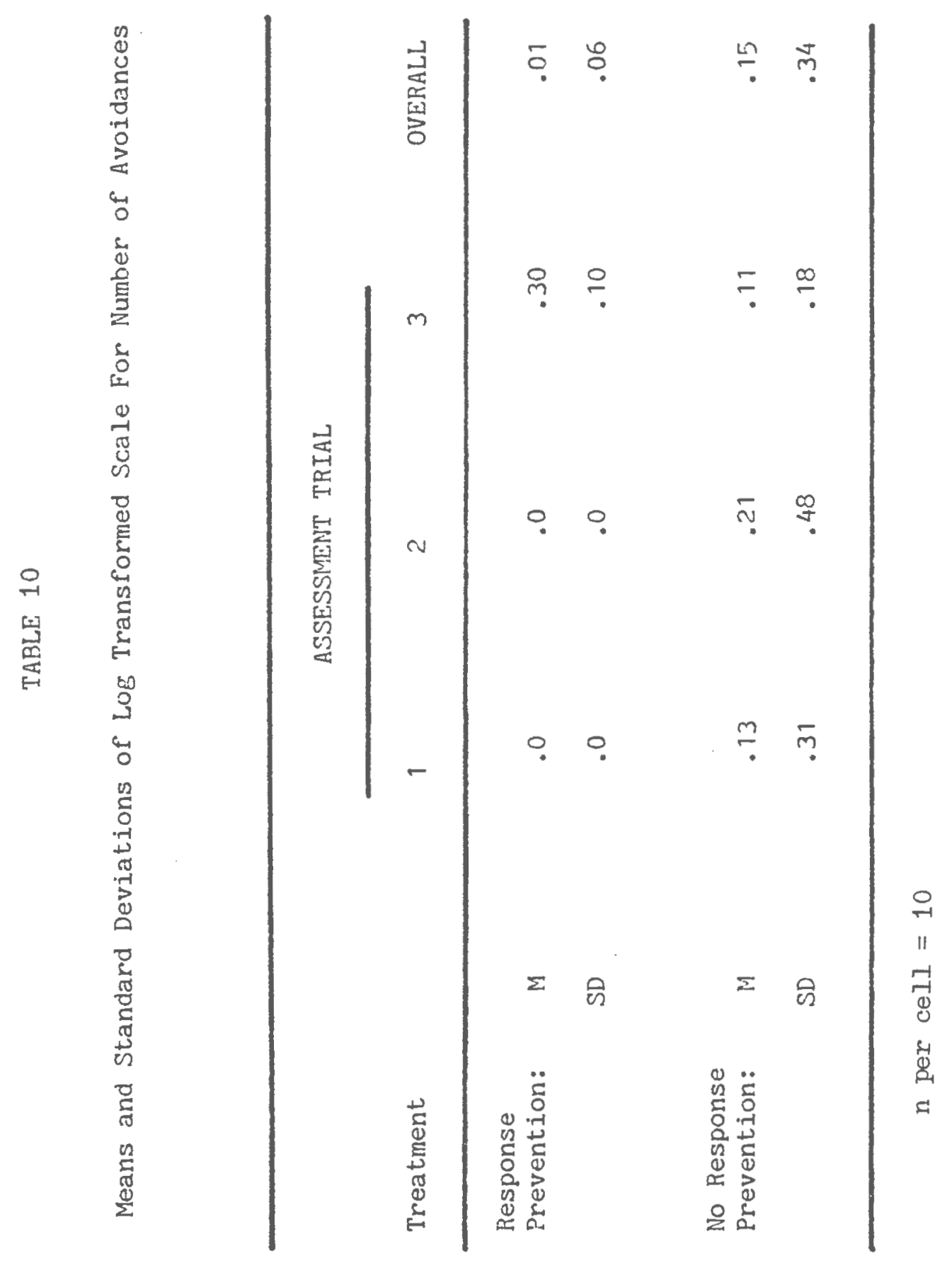


In order to explicitly examine the sensitivities of the various fear assessment variables in discriminating RP from NRP groups of subjects, a series of discriminant function analyses were performed. The first analysis employed a direct solution which simultaneously compared all six fear assessment variables. The standardized discriminant weights presented in table 11 clearly shows that approach latency had the highest loading $(.76)$, and appears to account for most of the variance in discriminating the treatment groups. Number of avoidances and number of safety rests both shared the next highest loading (.21). This discriminant function correctly predicted group membership for 70 of the subjects. Seventy seven percent of the RP group were correctly classified whereas 63 of the NRP group were correctly classified. Although the direct solution of discriminant analysis presented above clearly shows that approach latency was the most sensitive measure, it is possible that the addition of one or more variables would, in the multivariate sense, aid in discriminating the effects of RP. To further examine this possibility, a stepwise 


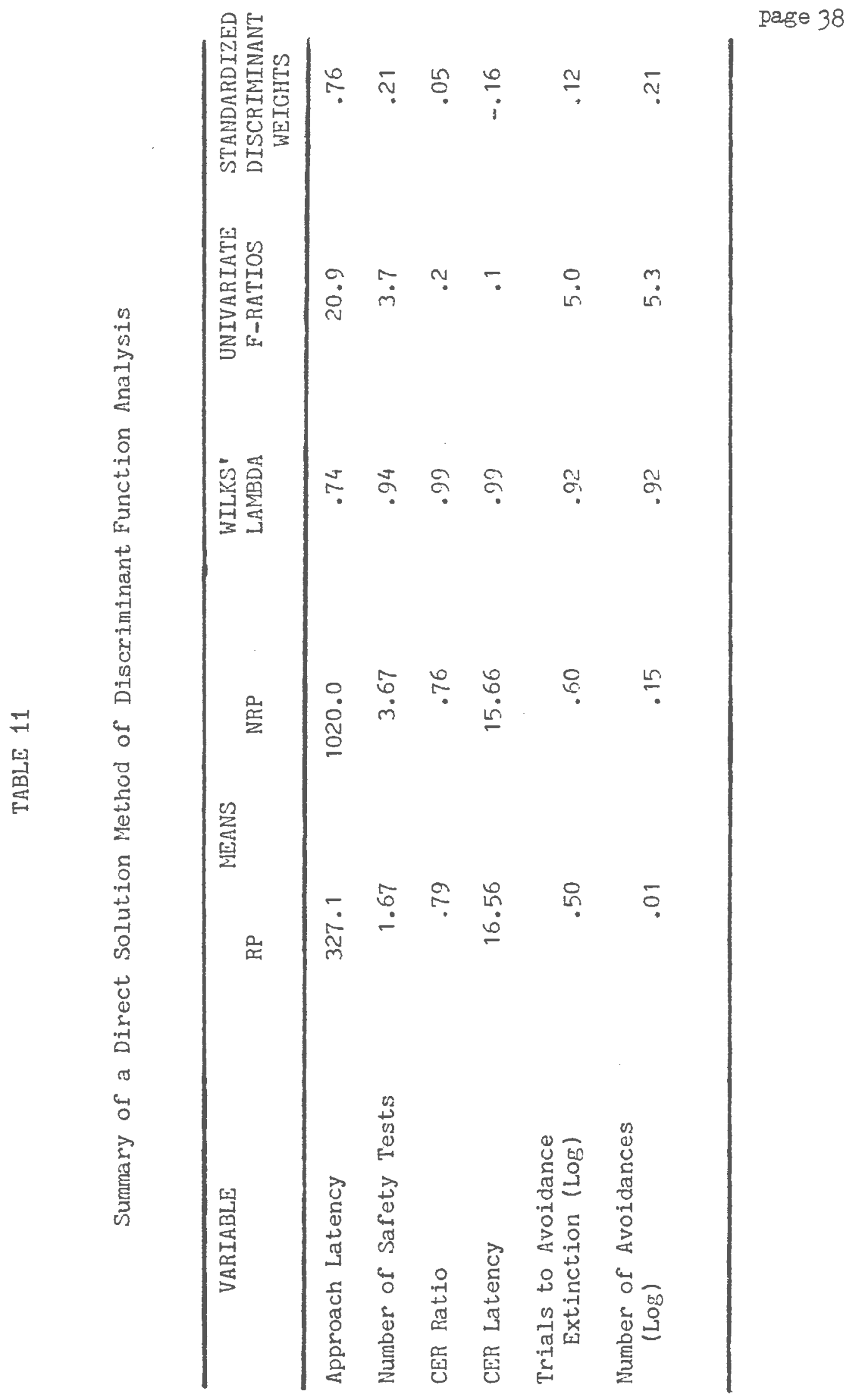


solution of discriminant function analysis was performed. This analysis employed maximum changes in Rao's $V$ as criteria for including variables into the analysis. The stepwise procedure began by selecting the variable which most clearly discriminated the two groups. The analysis next searched for the second most discriminating variable. A variable was retained in the analysis only if it significantly added discriminating power to the equation. Not surprisingly, approach latency was entered first into the discriminant equation. However, no other variable significantly contributed to the equation. (The stepwise procedure included trials to avoidance extinction as its second variable. For this analytic step, the change in Rao's $v$ was 1.73 with an associated significance level of only .188$.

Relationships Among the Assessment Variables

Clearly, research in RP has assumed that all three assessment procedures reflect a measurement of fear. This study explicitly tested this assumption by employing correlational and factor analytic techniques to examine the relationships among the variables. The 
page 40

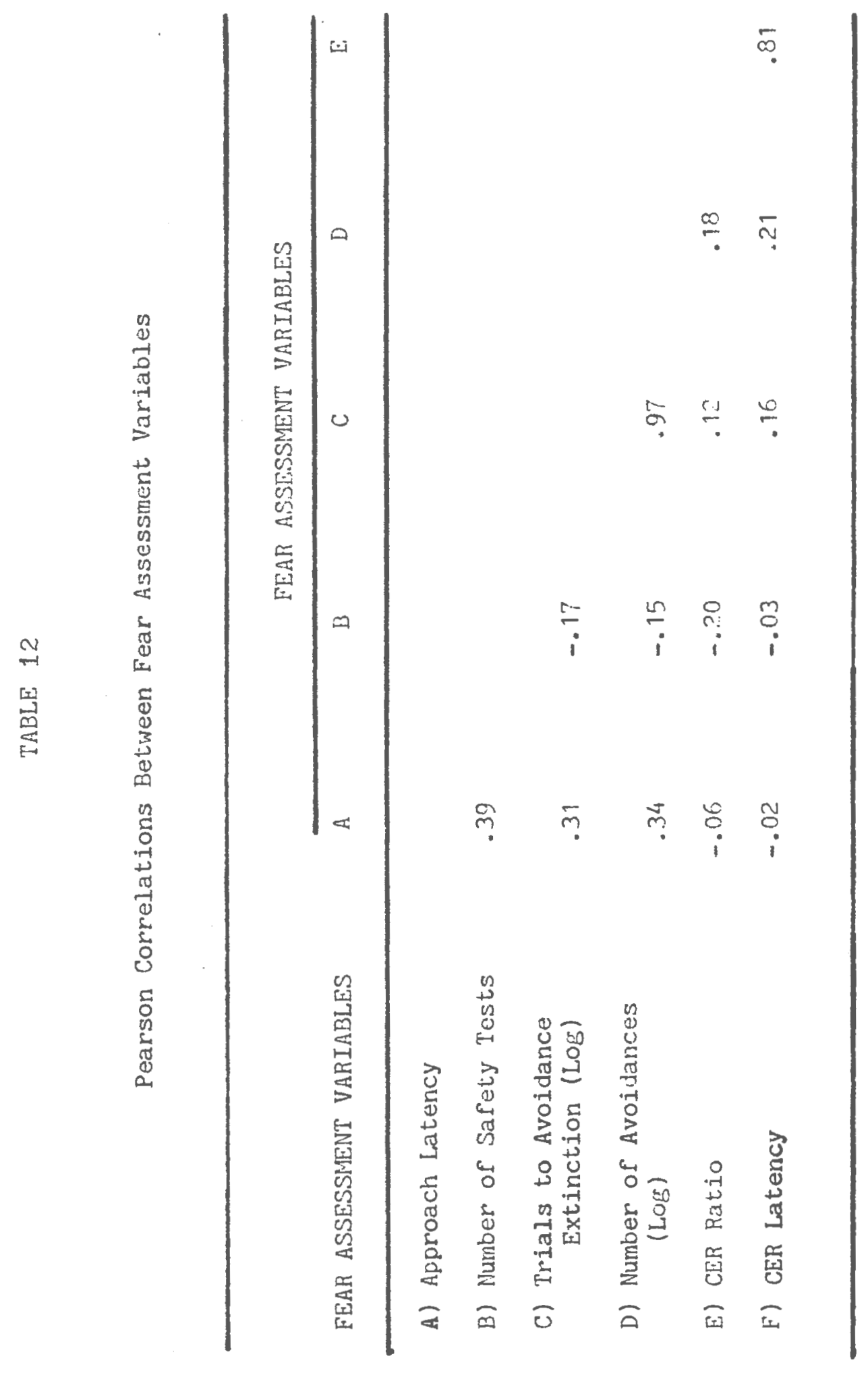


correlations among the six fear assessment variables are shown in Table 12. Not surprisingly, the highest correlations are found between the pair of variables within each assessment procedure. The correlation between the two avoidance assessment variables was .97 and between the two CER variables was .8I. The lowest "within" procedure correlation was between the approach variables (.38). Particularly noteworthy is the apparent lack of correlation between assessment procedures.

To further examine the apparent lack of relationship between the assessment procedures, the correlation matrix found in Table 12 was subjected to a principal component analysis. Table 13 shows the results of this analysis. Using a criteria of eigenvalues greater than unity for extracting components, three highly discreet and interpretable components emerged from this analysis. These three components accounted for $87 \%$ of the total variance. Component I clearly reflects avoidance behavior. Trials to avoidance extinction and number of avoidances had loadings of .974 and .977 on this component. Component 
TABLE 13

Results of a Principal Component Analysisa

of the Fear Assessment Variables

\begin{tabular}{|c|c|c|c|c|}
\hline \multirow[t]{2}{*}{ VARIABLE } & \multicolumn{3}{|c|}{ COMPONENT } & \multirow[t]{2}{*}{ COMMUNALITY } \\
\hline & I & II & III & \\
\hline $\begin{array}{c}\text { Trials To Avoidance } \\
\text { Extinction }\end{array}$ & .974 & .067 & .022 & .954 \\
\hline Number of Avoidances & .977 & .122 & .023 & .970 \\
\hline CER Ratio & .076 & .941 & -.127 & .907 \\
\hline CER Latency & .089 & .951 & .029 & .914 \\
\hline Approach Latency & .399 & -.044 & .768 & .752 \\
\hline $\begin{array}{l}\text { Number of Safety } \\
\text { Tests }\end{array}$ & -.222 & -.053 & .881 & .829 \\
\hline$\%$ Variance ${ }^{b}$ & .355 & .302 & .230 & \\
\hline Cum. \% Variance ${ }^{b}$ & .355 & .657 & .887 & \\
\hline
\end{tabular}

a) These results are of a varimax rotated factor matrix.

b) These values were computed from the rotated matrix. The eigenvalue associated with components IV, V, and VI before rotation were $.479, .167$, and .030 . 
II clearly reflects CER behavior. CER Ratio and CER Latency possessed loadings of .941 and .951 on this component. The third component is clearly represented by approach behavior. Approach latency and number of safety tests had loading of .768 and .881 on this component.

The clarity of this factor structure should be stressed. No variable, with the mild exception of approach latency had appreciable factor loadings on more than one component. Approach latency had a loading of .399 on component $I$. This is the only variable which appears to share any communality with other variables outside its own assessment procedure.

\section{Further Examination of the Measures.}

CER Ratio's. The present study was also designed to assess the relative sensitivity of using 10 sec., 20 sec.. or $30 \mathrm{sec}$. samples of behavior in computing CER ratios. The CER ratios computed from 30 sec. ratios reported in an earlier section failed to show differences between the RP and NRP groups. In fact, the ratios appeared nearly equal for both groups. The three 
variables, when subjectea to a discriminant function analysis, failed to reveal a significant discriminant function (Wilks' Lambda $=.97, \mathrm{P}=.90$ ). Table 14 shows the means for each group for each of the different durations and associated Wilks' lamida's and univariate F's.

Fear Acquisition and Assessment. In order to gain an understanding of the relationship between the acquisition of avoidance behavior and the subsequent assessment of "fear", intercorrelations between the four acquisition variables and the six assessment variables were computed. Table 15 shows these correlations. Of the 24 correlation coefficients, only the correlation between shocked trials and approach latency was significant $(r=-.27, g<.05)$. Given the substantial number of coefficients, this one significant finding could be expected by chance alone. When the alpha level is adjusted for an experiment-wise alpha of .05 (cf. Winer, 1971, p. 199), this correlation becomes nonsignificant. Thus, it appears that the various measures of "fear" are not related to avoidance training performance variables. 
page 45

TABLE 14

Resilts of a Direct Solution of Discriminant Flanction Analysis For Three Different Sample Durations

\begin{tabular}{|c|c|c|c|c|}
\hline \multirow[b]{2}{*}{$\begin{array}{l}\text { VARIABLE } \\
\text { (CER Ratios) }\end{array}$} & \multicolumn{2}{|c|}{ MEAIS } & \multirow[b]{2}{*}{ 'ILKS' LAMBDA } & \multirow[b]{2}{*}{$\begin{array}{c}\text { UNIVARIATE } \\
F\end{array}$} \\
\hline & $\mathrm{RP}$ & NRP & & \\
\hline 10 sec. samples & .803 & .770 & .997 & .168 \\
\hline $20 \mathrm{sec}$. samples & .797 & .781 & .923 & .091 \\
\hline 30 sec. samples & .788 & .763 & .996 & .210 \\
\hline
\end{tabular}




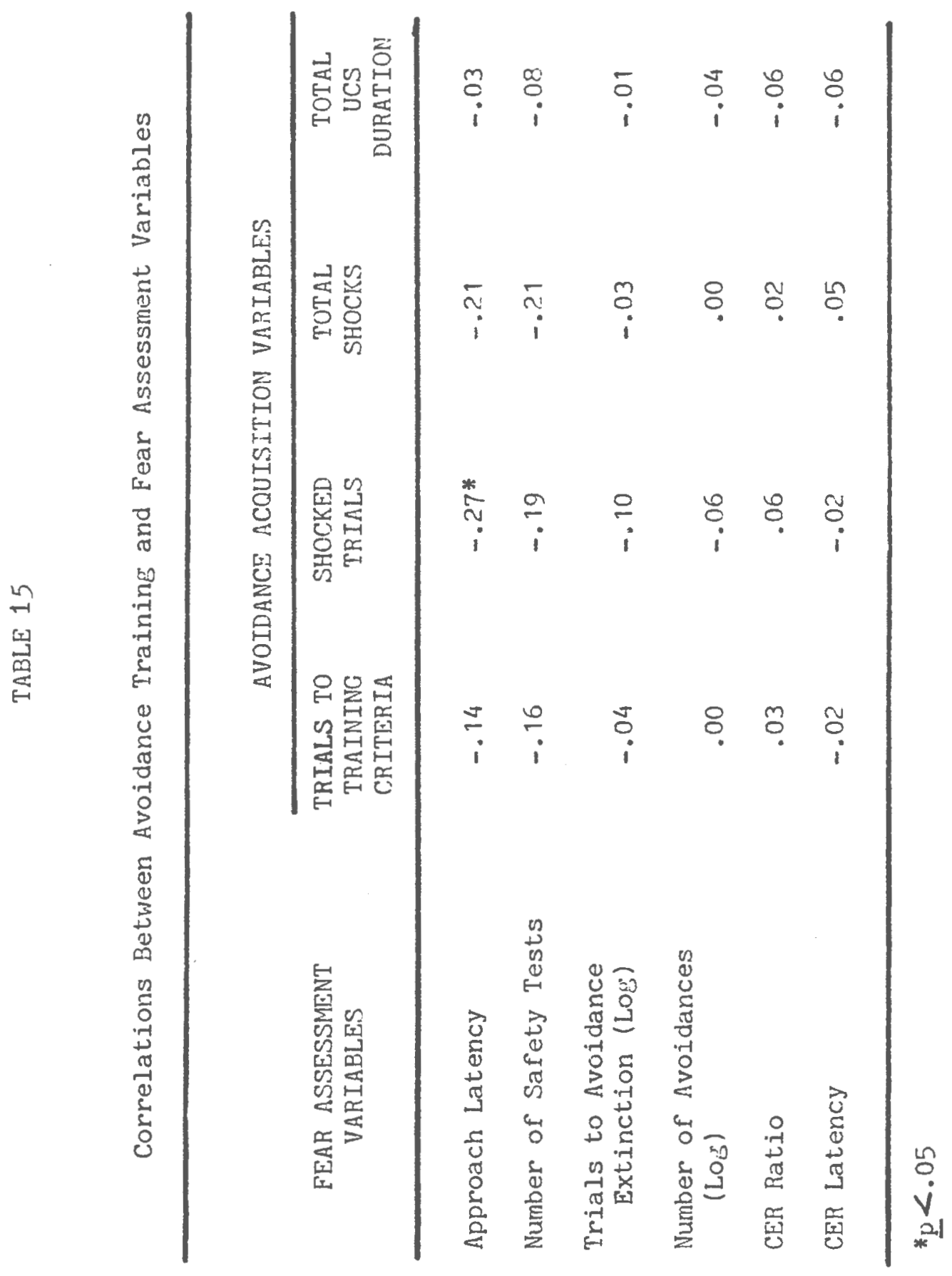




\section{DISCUSSION}

The complete lack of reactivity of measurement for all dependent variables permitted the inclusion of all subjects in all subsequent analyses. This finding, however, is somewhat disparate with an earlier position taken by corriveau \& Smith (1978) which posited that approach behavior in general and safety-test behavior in particular might represent a process of fear reduction. This view would lead to the prediction that the approach procedure in the present study would show reactivity of measurement. This apparent discrepancy, however, should be examined cautiously, since this study was designed to minimize the risk of reactivity. Specifically, the approach assessment procedure was terminated as soon as the subjects approached the grids, whereas subjects in the corriveau and smith study were allowed to freely ascend and descend the platform within a 5 hr. fear test. Nonetheless, the lack of reactivity was helpful in pursuing the major questions examined in the present investigation.

The results of the individual fear assessment variables were particularly interesting. Of the three assessment techniques, both the approach and the avoidance procedures showed significant differences 
between the RP and NRP groups, while the CER procedure failed to discriminate the groups.

of the two approach variables, the sensitivity of approach latensy was the more striking. This variable showed the greatest treatment effect and, not surprisingly, was the best discriminator in a discriminant function analysis (discussed separately below). The sensitivity of approach latency in discriminating the effects of RP is consistent with other studies using the approach technique (Bersh \& Paynter, 1972; Corriveau, Contildes \& Smith, 1978; Corriveau \& Smith, 1978; Shipley, Mock \& Levis, 1971; Wilson \& Dinsmoor, 1970). Although the second approach assessment variable, number of safety tests, was less sensitive than approach latency, it should be noted that the approach procedure in this study presented a conservative test of this variable. It should be remembered that animals that did not approach the grids within $30 \mathrm{~min}$. received a ceiling score of 1820 sec. consequently, many of these animals had not yet engaged in a safety-test response. Also, those animals which did not approach but emitted at least one safety-test might have safety tested more frequently had they been given sufficient time to approach the grids. A closer 
page 49

examination of the data revealed that only three of the RP subjects failed to approach the grids whereas 10 of the NRP subjects failed to do so. Thus, al though the design of this study attenuated the sensitivity of the safety test variable, NRP subjects were still shown to emit significantly more safety test responses.

The two avoidance assessment variables, subjected to a common logarithmic transformation, both showed significant differences between the treatment groups. These differences, though, were not as great as they were for approach latency. A close inspection of these data revealed that although the data were on the whole similar to other studies using the avoidance procedure with a one-way platform apparatus (Baum, 1966, 1969a, 1969b, 1972; Lederhendler \& Baum, 1970; Siegeltuch \& Baum, 1971), NRP subjects appeared to reach extinction criteria more rapidy. Surprisingly, the aistribution of trials to avoidance extinction was appreciably skewed for both groups; the majority of both RP and NRP subjects failed to avoid whatsoever. At first glance, the surprisingly low avoidance rate, particularly for NRP subjects, is quite puzzling. Several explanations, however, are plausble.

First, this study is one of relatively few studies 
which employed a protracted duration of RP. The majority of studies using RP employed a RP Juration of only 5 min. (cf. Baum, 1970; Smith, Dickson \& Sheppard, 1973). In a parametric study, Baum (1969a) found 30 min. of RP sufficient in completely reducing fear as measured by avoidance extinction when $1.3 \mathrm{~mA}$ shock was used. In comparison to these studies, the $45 \mathrm{~min}$. duration of $R P$ in the present stuay was quite long.

Secondly, as described in the introduction, it should be noted that several of the earlier RP studies inadvertently confounded RP with the passage of time. Response prevention procedures were applied for a certain duration between training and testing phases of the procedure, whereas subjects not receiving RP were tested for fear reduction immediately after avoidance training. In other words, RP consisted of a physical procedure plus the passage of time while NRP consisted of no physical treatment and no passage of time. The present study obviated this confound by equating the passage of time across treatment groups.

Thirdly, avoidance assessment in this study actually began either 45 min., 75 min., or 105 min. after avoidance training. Conceivably, the avoidance data could have been influenced by what is referred to 
in the literature as the "Kamin Effect" (Denny \& Ditchman, 1962; Kamin, 1957) or the "Warm-Up Effect" (Foree \& LoLordo, 1974; Hineline, 1978; Klein \& Rilling, 1972, 1974; Powell, 1976). Briefly, the Kamin Effect refers to a decrement in avoidance responding between sessions of avoidance training. Kamin (1957) interrupted avoidance training for either 0,1 , or 24 hr. and found that when training was resumed, performance was less proficient after interruption of 1 hr. than after $24 \mathrm{hr}$. or no interruption at all. The Warm-Up Effect specifically explains the decrement in avoidance behavior during the early part of any training session as compared to either late in its preceding session of later in its current session. Hineline (1978) used inter-session intervals of $0,15,30,60$, 93, 120 and $240 \mathrm{~min}$. and found an appreciable warm-up effect with a 39 min. interruption, yet, avoidance decrements were maximum with 5 n to $120 \mathrm{~min}$. interruptions. Thus, the avoidance rate of the present data may be attenuated because of the kamin or warm-up effect.

A fourth explanation is offered by the competing response interpretation which speculates that animals which are not avoiding may be doing so either because 
they are not fearful or because other responses (i.e. freezing) have been reinforced. Indeed, observations by the present author strongly suggest that the majority of subjects who were not avoiding were, in fact, freezing at the CS onset.

A fifth and final explanation simply maintains that the avoidance methodology is comparatively not sensitive to residual fear. The protracted duration between training and testing may itself have reduced fear to a level not measurable by the avoidance methodology. This explanation is supported by the results of Corriveau and Smith (1978) who, using a $1 \mathrm{hr}$. RP duration, found a significant difference between control and RP subjects using approach latency but failed to find a significant difference using a variable similar to the avoidance procedure.

The apparent inability of both CER measures in demonstrating a significant treatment effect is more perplexing. First, these results are disparate with other studies which did reveal significant RP effects using the CER procedure (Leaf, Kayser, Andrews, Adkins \& Leaf, 1968; Monti \& Smith, 1976; Rohrbaugh, Riccio \& Arthur, 1972; Shipley, 1974). Interestingly, the data of this study are consistent with the results of Bankart 
and Elliott (1974) who used trials to avoidance extinction and a CER suppression ratio as their dependent variables. Similar to the results of the present study, Bankart and Elliott found a significant RP effect when using trials to avoidance extinction but not when using CER suppression ratios.

A close inspection of the CER data is also interesting. As the means and standard deviations for both CER ratio and CER latency indicate, both RP and NRP groups behaved remarkably similarly. The mean CER ratios themselves suggest an "average" amount of suppression for both groups. A closer examination of these data, however, presents an entirely different picture. Few animals ever showed "average" suppression. For each treatment group, the distribution of the data was oddly U-shaped. Specifically, 14 RP subjects and 12 NRP subjects had suppression ratios greater than .98 while 9 RP and 11 NRP subjects had suppression ratios smaller than .60 (Ratios ranged between .5 and 1.0 with 1.0 reflecting complete suppression and .5 indicating complete lack of suppression.) Thus, over two-thirds of the subjects revealed CER ratios that fell on the endpoints of the distribution. These "outliers" were equally proportionate across treatment groups. Hence, 
most subjects from both groups showed either complete suppression or lack of it. It is perhaps this very variability which makes the CER variable less sensitive than both approach and avoidance procedures in demonstrating the effects of RP.

In fairness to advocates of the CER procedure, a potential criticism of the design of the present study should be discussed. Specifically, the white noise CS employed as the probe was not presented during RP, primarily because of the inherent difficulties encountered in establising RP parameters (i.e. proportion of CS time during total RP as a function of both CS durations and CS presentation frequencies). Empirical justification for excluding cs presentations during RP is found in the Monti and Smith (1976) study. Using a CER paradigm, these authors found that placing subjects in the apparatus without CS presentations was just as effective as placing subjects in the apparatus with CS presentations.

Collectively, the results of the univariate analyses suggest that the approach procedure yields the most sensitive assessment of RP effects. The avoidance procedure also demonstrated significant RP effects but appeared less sensitive than the approach procedure. 
Conversely, the CER variables appeared relatively insensitive in revealing RP effects.

The results of the discriminant analyses more succinctly compared the sensitivity of each dependent variable. The direct solution clearly showed that approach latency was the most sensitive variable. The stepwise solution of discriminant analysis revealed that only trials to avoidance extinction significantly aided approach latency in discriminating the effect of RP. These results provide an important contribution in demonstrating differential sensitivities among the dependent variables. The major implication of these findings is that the results of parametric investigations using different assessment procedures are, unfortunately, not comparable. Also unfortunate is the realization that the majority of RP investigations have employed the avoidance assessment procedure instead of the more sensitive approach assessment technique.

Perhaps the most interesting findings of this study are the results of the correlational and factor analytic analyses. To date, researchers in the RP area appear to have addressed the three fear assessment procedures analogously. At least at the conceptual level, all three methodologies have been cited as 
indices of fear. The results of the present study represents the first empirical challenge to this assumption. The principal component analyses clearly found three distinct and uncorrelated components of behavior. The foremost implication of this finding, that each assessment procedure is measuring a separate and aistinat construct, strongly attests to the incomparability of results across assessment procedures. These unexpected results raise a serious theoretical question -- namely, "What are these three distinct components?" Are they subcomponents of a general fear reaction or is fear actually reflected by any one of these assessment variables? Unfortunately, answers to these questions are, for the most part, beyond the scope of the present study. Questions such as these are best answered by systematic research designed to assess both the convergent and divergent validity of these variables with other variables thought to reflect fear (e.g. heart rate, freezing behavior, micturation, etc.). Nonetheless, the results of this study suggests that approach latency, the most sensitive variable in discrimination RP effects, may be the most valid index of fear. At the conceptual level, approach latency is the simplest variable to interpret. problematic 
features of interpretation for both the avoidance and CER procedures has already been aiscussed lCorriveau \& Smith, 1978). For one, the avoidance procedure appears confounded by competing responses. Subjects may no longer avoid after the introduction of a treatment, either because fear was reduced or because competing responses were instrumentally reinforced.

An interpretative problem with the CER procedure stems from the realization that the cS which guides and maintains avoidance behavior is actually quite complex. It should be noted that the informational value of the artificially imposed $c s$ is actually quite redundant with a panoply of contextual (i.e. apparatus or environmental cues) and interoceptive stimuli. Monti and Smith (1976), for example, demonstrated that the role of apparatus cues during RP was at least equally important to the role of the discrete $C S$ in reducing fear. Also, researchers using different apparatae generally show superior avoidance acquisition when environmental cues are maximized (i.e. one-way avoidance is generally superior to two-way avoidance which in turn is generally superior to Sidman-type avoidance procedures). Consequently, the discrete cs-probe employed in a CER procedure may represent only a sinall proportion of the 
actual CS complex. This notion may account for the significant inter-subject variability in the present study's CER data. It is conceivable that some subjects employed the discrete CS's informational value during avoidance acquisition while other subjects relied more extensively on apparatus cues. This would explain why most animals showed either complete suppression or complete lack of suppression.

Another interesting result of the correlational analyses is that the pair of approach assessment variables were less correlated to each other than either the pair of avoidance or CER variables were to each other. In fact, the high correlation between the two avoidance assessment variables $(r=.97)$ makes the individual analyses of variance on these two variables completely redundant with each other. This redundancy also applies to the CER variables although to a lesser degree $(r=.81)$. These results suggest that the approach procedure may possess the advantage of recording two non-redundant variables. It should be interesting to see whether future research could isolate parameters which could independently influence these dependent variables. Since different theorists have proposed the existence of different components or 
processes involved in the acquisition of avoidance behavior (e.g. Mowrer, 1950; Seligman Johnston, 1973), it would behoove avoidance theorists to isolate and identify these components. Seligman and Johnston (1973) for example, posit the importance of both emotional and cognitive components in maintaining avoidance behavior. Although much research is needed to empirically differentiate these components, the notion of using safety testing behavior as an indicator of a cognitive component has already been entertained (corriveau, 1977).

Together, the finding of independence among the assessment variables and the apparent superiority of the approach procedure cast considerable doubt on the majority of RP research. As a case in point, Baum and his colleagues have extensively investigated several techniques which increased the efficacy of RP. These techniques included the presence of nonfearful rats (Baum, 1969), mechanically moving the animals during RP (Lederhendler \& Baum, 1970), delaying RP (Baum, 1972), presenting intracranial stimulation of the brain (Gordon \& Baum, 1971), applying a loud buzzer (Baum \& Gordon, 1970) and supplying nest building materials (Reynierse \& Straw, 1974). It should be noted that these studies 
invariably employed the avoidance procedure to assess fear. Conceivably, these techniques may have simply reduced the confounding effects of competing responses (i.e. animals which were moved around during RP would have been prevented from freezing). Unfortunately, only one study has attempted to replicate Baum's findings using the approach procedure. Corriveau, Contildes and Smith (1978) replicated Baums's social facilitation procedure and found it ineffective when assessed with the approach procedure.

Although inferences from animal research to clinical application should always be made cautiously, the independence of the three assessment methodologies found in the present study merits comparison to clinical research. First, it is interesting that the majority of behaviorally oriented research on human avoidance behavior has employed an approach assessment procedure. These procedures typically include measures of the proximity to which a phobic stimulus (e.g. live snake) is approached (Foa, Blau, prout \& Latimer, 1977); Gauthier \& Marshall, 1977; Hodgson \& Rachman, 1970; Mathews \& Shaw, 1973; Stone \& Borkovek, 1975; Sue, 1975). Thus on purely conceptual grounds, the approach assessment procedure used in the present study is most 
analogous to clinical research.

A second similarity is that, to date, clinical research has not addressed the independence of avoidance, approach and CER methodologies. In an interesting paper on a related subject, Hayes (1976) has addressed the independence of both avoidance and approach contingencies in human avoidance behavior. Yet, the distinctiveness of the different assessment methodologies has not yet received sufficient attention in the clinical setting. As a case in point, the clinical studies cited above clearly used an approach assessment procedure, recording the extent to which subjects freely approached a phobic stimulus. (Note that an avoidance procedure would necessitate a complete presentation of the phobic stimulus and the recording of subsequent avoidance responding.) Yet, this approach procedure has been cited in the literature (cf. Levis \& Hare, 1977) as the Behavioral Avoidance Test (BAT).

If the results of this study can be extended to clinical studies, it is encouraging to note that clinical research appears to have incorporated the most sensitive assessment procedure. For theoretical purposes, however, it would be interesting to empirically examine the relationship of different 
behavioral assessment procedures with a clinical population. Although the relative independence among the BAT and other modes of assessment (i.e. physiological and self-report) has already been established (Hodgson \& Rachman, 1974; Lang, 1970, 1977; Rachman, 1976, 1977; Rachman \& Hodgson, 1974; Sartory, Rachman, \& Grey, 1977; Suarez, Crowe \& Adams, 1978) it would also be interesting to compare the relationship between avoidance and CER-type variables with physiological and self-report variables. 
page 63

REFERENCES

Ayer, w. Implosive Therapy: A review. Psychotherapy: Theory, Research and Practice, 1972, 9, 242-255.

Bandura, A. Princioles of Behavior Modification, New York: Holt, Rinehart and winston, Ine., 1959.

Bankart, B. and Elliott, R. Extinction of avoidance in rats: Response availability and stimulus

presentation effects. Behaviour Research and Therapy, 1974, 12, 53-56.

Baum, M. An automated apparatus for the avoidance training of rats. Psychological Reports, 1965, 16, $1205-1211$.

Baum, M. Rapid extinction of an avoidance response following a period of response prevention in the avoidance apparatus. Psychological Reports, 1955, $18,59-64$.

Baum, M. Efficacy of response prevention (flooding) in facilitating the extinction of an avoidance response in rats: The effect of overtraining the response. Behaviour Research and Therapy, 1968, 6, $197-283$. 
page 64

Baum, M. Extinction of an avoidance response following response prevention: Some parametric investigations. Canadian Journal of Psychology, 1969 (a), 23, 1-10.

Baum, M. Extinction of an avoidance response motivated by intense fear: Social facilitation of the action of response prevention (flooding) in rats. Behavior Research and Therapy, 1969(b), 7, 57-62.

Baum, M. Extinction of avoidance responding through response prevention (flooding). Psychological Bulletin, 1970, 74, 276-282.

Baum, M. Flooding (response prevention) in rats: The effects of immediate vs. delayed flooding and of changed illumination conditions during flooding. Canadian Journal of Psychology, 1972, 26, 190-200.

Baum, M. \& Gordon, A. Effect of a loud buzzer applied during response prevention (flooding) in rats. Behaviour Research and Therapy, 1970, 8, 287-292.

Baum, M. \& Higgins, J. A. Extinction of an avoidance response through response prevention (flooding) in the guinea pig. Psychonomic science, 1971, 25, 3-4. Baum, M. Poser, E. Comparison of flooding procedures 
in animals and man. Behavior Research and Therapy, 1971, 9, 249-251.

Berman, J. \& Katsev, R. Factors involved in the rapid elimination of avoidance behavior. Behavior

Research and Therapy, 1972, 19, 247-255.

Bersh, P. J. \& Paynter, W. E. Pavlovian extinction of avoidance responses under curare. Journal of Comparative and physiological psychology, 1972, 51, 519-524.

Bolles, R. C. Learning Theory. New York: Holt, Rinehart and winston, $1975 \mathrm{a}$.

Bolles, R. C. Theory of Motivation, 2nd ed. New York: Harper and Row, $1975 \mathrm{~b}$.

Corriveau, D. P. UCS intensity and safety testing behavior following response prevention. Paper presented to the Eastern Psychological Association, April, 1977.

Corriveau, D. P., Contildes, K. \& Smith, N. F. Social facilitation following response prevention in the rat. Psychological Reports, 1978, 43, 127-133.

Corriveau, D. P. \& Smith, N. F. Fear reduction and safety testing behavior following response 
prevention: A multivariate analysis. Journal of Experimental Psychology: General, 1978, 107, 145-158.

Coulter, S., Riccio, D. \& Page, H. Effects of blocking an instrumental avoijance response. Journal of Comparative and Physiological Psychology, 1969, 68, $377-331$.

Denny, M. R. \& Ditchman, R. E. The locus of maximal "Kamin effect" in rats. Journal of Comparative and Pnysiological Psychology, 1962, 55, 1069-1970.

Foa, E. B., Blau, J. S., Prout, M. \& Latimer, P. Is horror a necessary component of flooding (implosion)? Behavior Research and Therapy, 1977, 15, $397-492$.

Foree, D. D. L LoLordo, V. M. Transfer of control of the pigeon's key peck from food reinforcement to avoidance of shock. Journal of the Experimental Analysis of Benaviour, 1974, 22, 251-259.

Gauthier, J. \& Marshall, W. L. The determination of optimal exposure to phobic stimuli in flooding therapy. Behaviour Research and Therapy, 1977, 15, $403-410$. 
Gordon, A. \& Baum, M. Increased efficacy of flooding (response prevention) in rats through positive intracranial stimulation. Journal of Comparative and Physiological Psychology, 1971, 75, 68-72.

Hayes, S. C. The role of approach contingencies in phobic behavior. Behavior Therapy, 1976, 7, 28-36. Herrnstein, R. J. Method and theory in the study of avoidance. Psychological Review, 1969, 76, 49-59. Herrnstein, R. J. \& Hineline, P. N. Negative reinforcement as shock-frequency reduction. Journal of the Experimental Analysis of Behavior, 1965, 9, 421,430 .

Hineline, P. N. Warmup in avoidance as a function of time since prior training. Journal of the Experimental Analysis of Behavior, 1978, 29, $87-103$.

Hodgson, R. \& Rachman, S. An experimental investigation of the implosive technique. Behavior Research and Therapy, 1970, 8, 21-27.

Hodgson, R. J. \& Rachman, S. Desynchrony in measures of fear. Behaviour Research and Therapy, 1974, 12; 319-326. 
Hogan, R. A. The implosive technique. Behaviour Research and Therapy, 1968, 6, 423-432.

Hogan, R. A. Implosively orientated behavior modification: Therapy considerations. Behavior Research and Therapy, 1969, ㄱ, 177-183.

Kamin, L. J. Retention of an incompletely learned avoidance response. Journal of Comparative and Physiological Psychology, 1957, 50, 457-469.

Kamin, L. J. Brimer, C. J. and Black, A. H. Conditioned suppression as a moniter of fear of the $C S$ in the course of avoidance training. Journal of Comparative and physiological Psychology, 1963, 56, 497-501.

Klein, M. \& Rilling, M. Effects of response-shock interval and shock intensity on free-operant avoidance responding in the pigeon. Journal of the Experimental Analysis of Behavior, 1972, 18, 295-303.

Klein, M. \& Rilling, M. Generalization of free-operant avoidance behavior in pigeons. Journal of the Experimental Analysis of Behavior, 1974, 21, 75-83. Lang, P. Stimulus control, response control, and 
desensitization of fear. In Levis, D. (Ed.)

Learning Approaches to Therapeutic Behaviour Change. Aldine Press, Chicago, 1970.

Lang, P. J. Imagery in therapy: An information processing analysis of fear. Behavior Therapy, $1977,8,852-885$.

Leaf, R. C., Kayser, R. J., Andrews, J. A., Adkins, J.w. \& Leaf, S. R. P. Block of fear conditioning induced by habituation or extinction. Psychonomic science, $1968,10,189-190$.

Lederhendler, I. \& Baum, M. Mechanical facilitation of the action of response prevention (flooding) in rats. Behaviour Research and Therapy, 1970, 8, $43-48$.

Levis, D. Implosive therapy: The subhuman analogue, the strategy, and the technique. V. A. Publication, Battle Creek, Michigan, 1965.

Levis, D. J. Learning approaches to therapeutic behavior change, Chicago: Aldine Publishing Co., 1979.

Levis, D. J. Implosive therapy: A critical analysis of Morganstern's review. Psychological Bulletin, 1974, 81, 155-158. 
Levis, D. J. \& Hare, N. A review of the theoretical rationale and empirical support for the extinction approach of implosive (flooding) therapy. In Eisler, R. M. \& P. M. Miller (Eds.) progress in Behaviour Modification, IV. New York: Academic Press, 1977.

Linton, J., Riccio, D., Rohrbaugh, M. \& Page, H. The effects of blocking an instrumental avoidance response: Fear reduction or enhancement. Behavior

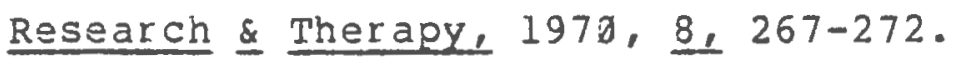

Mathews, A. \& Shaw, P. Emotional arousal and persuasion effects in flooding. Behavior Research and Therapy, $1973,11,587-593$.

Marrazo, M. Riccio, D. C. \& Riley, J. Effects of Pavlovian conditioned stimulus-unconditioned stimulus pairings during avoidance response prevention trials in rats. Journal of Comparative and Physiological Psychology, 1974, 86, 96-100. McCutcheon, B. A. \& Adams, H. E. The physiological basis of implosive therapy. Behaviour Research and Therapy, 1975, 13, 93-100.

Monti, P. M. \& Smith, N. F. Residual fear of the 
page 71

conditioned stimulus as a function of response prevention after avoidance or classical defensive conditioning in the rat. Journal of Experimental Psychology, $1976,105,148-162$.

Morganstern, K. Implosive therapy and flooding

procedures: A critical review. Psychological Bulletin, 1973, 79, 318-334.

Morganstern, K. P. Issues in implosive therapy: Reply to

Levis. Psychological Bulletin, $1974,81,389-382$.

Mowrer, 0 . Learning theories and personality dynamics. New York: The Ronald Press, 1950.

Page, H. The facilitation of experimental extinction by response prevention as a function of the acquisition of a new response. Journal of Comparative and Physiological Psychology, 1955, $48,14-16$

Page, H. \& Hall, J. Experimental extinction as a function of the prevention of a response. Journal of Comparative and Physiological Psychology, 1953, $46,33-34$.

Powell, R. W. A comparison of signalled vs. unsignalled free operant avoidance in wild and domesticated 
rats. Animal Learning and Behavior, 1976, 生 $279-286$.

Rachman, S. Treatment by prolonged exposure to high intensity stimulation. Behaviour Research and Therapy, 1968, 6, 159-166.

Rachman, S. The passing of the two-stage theory of fear and avoidance. Behaviour Research and Therapy, $1976,14,125-132$.

Rachman, S. The conditioning theory of fear-acquisition:

A critical examination. Behaviour Research and Therapy, 1977, 15, 375-387.

Rachman, S. \& Hodgson, R. Synchrony and desychrony in fear and avoidance. Behaviour Research and Therapy, $1974,12,311-318$.

Reynierse, J. H. \& Straw, M. k. Effects of progesterone and nesting materials on response prevention and extinction of avoidance in rats. Behaviour Research and Therapy, 1974, 12, 175-180.

Reynierse, J. H. \& Wiff, L. I. Effects of temporal placement of response prevention on extinction of avoidance in rats. Behaviour Research and Therapy, $1973,11,119-124$. 
Riccio, D. C. \& Silvestri, R. Extinction of avoidance behavior and the problem of fear. Behaviour Research and Therapy, 1973, 11, 1-9. Rohrbaugh, M. Riccio, D. C. \& Arthur, A. Paradoxical enhancement of conditioned suppression. Behaviour Research and Therapy, 1972, 10, 125-130.

Sartory, G. Rachman, S. \& Grey, S. An investigation of the relation between reported fear and heart rate. Behaviour Research and Therapy, 1977, 15, 435-438. Schiff, R., Smith, N. \& Prochaska, J. Facilitation of extinction of an avoidance response by response blocking. Journal of Comparative and Physiological Psychology, $1972,81,356-359$.

Seligman, M. E. P. \& Johnston, J. C. A cognitive theory of avoidance learning. In F. J. McGuigan \& D. B. Lumsden (Eds.), Contemporary approaches to conditioning and learning. Washington, D. C. : V. H. Winston, 1973 .

Shipley, R. H. Extinction of conditioned fear in rats as a function of several parameters of CS exposure. Journal of Comparative And Physiological Psychology, $1974,87,699-707$. 
Shipley, R. H., Mock, L. A., \& Levis, B. J., Effects of several response prevention procedures on activity, avoidance responding, and conditioned fear in rats. Journal of Comparative and physiological Psychology, 1971, 77, 256-279.

Siegeltuch, M. \& Baum, M. Extinction of well established avoidance responses through response prevention (flooding). Behaviour Research and Therapy, 1971, 9. $103-108$.

Smith, R. D., Dickson, A. L. \& Sheppard, L. Review of flooding procedures (Implosion) in animals and man. Perceptual and Motor Skills, 1973, 37, 351-374.

Solomon, R., Kamin, L. \& Nynne, L. Traumatic avoidance learning: The outcomes of several extinction procedures with dogs. Journal of Abnormal and Social Psychology, 1953, 48, 291-302.

Solomon, R. L. \& Wynne, L. C. Traumatic avoiảnce learning: The principles of anxiety conservation and partial irreversibility. The Psychological Review, 1954, 61, 353-384.

Stampfl, T. Implosive therapy: The theory. V. A. Publication, Battle Creek, Michigan, 1966. 
Stampfl, T. \& Levis, D. The essentials of implosive therapy: A learning theory based psychodynamic behavioral therapy. Journal of Abnormal Psychology, $1967,72,496-503$.

Stampfl, T. G. \& Levis, D. J. Implosive therapy - A behavioral therapy? Behaviour Research and Therapy, $1958, \underline{6}, 31-36$.

Staub, E. Duration of stimulus exposure as determinant of the efficiency of flooding procedures in the elimination of fear. Behaviour Research and Therapy, 1968, 6, 131-132.

Stone, N. M. \& Borkovek, T. D. The paradoxical effect of brief CS exposure on analogue phobic subjects. Behaviour Research and Therapy, 1975, 13, 51-54. Suares, Y., Crowe, M. J. \& Adams, H E. depression: Avoidance learning and physiological correlates in clinical and analogue populations. Bahavior Research and Therapy, 1978, 16, 21-31.

Sue, D. The effect of duration of exposure on systematic desensitization and extinction. Behaviour Research and Therapy, 1975, 13, 55-50.

Testa, T. J. Comments on: Residual fear of the 
conditioned stimulus as a function of response prevention after avoidance or classical defensive conditioning in the rat. Journal of Experimental Psychology: General, 1976, 105, 163-168.

Tortora, D. F. \& Denny, M. R. Flooding as a function of shock level and length of confinement. Learning and Motivation, 1973, 4, 276-283.

Voss, E., Mejta, D. \& Reid, L. Methou of deconditioning persisting avoidance: Response prevention and counterconditioning after extensive training. Bulletin of the Psychonomic Society, 1974, 3 , $345-347$.

Wilson, E. H. \& Dinsmoor, J. A. Effect of feeding on "fear" as measured by passive avoidance in rats. Journal Comparative and Phsiological Psychology, $1970,70,431-436$.

winer, B. J. Statistical principles in experimental design, 2nd ed. New York: McGraw-Hill, 1971. 


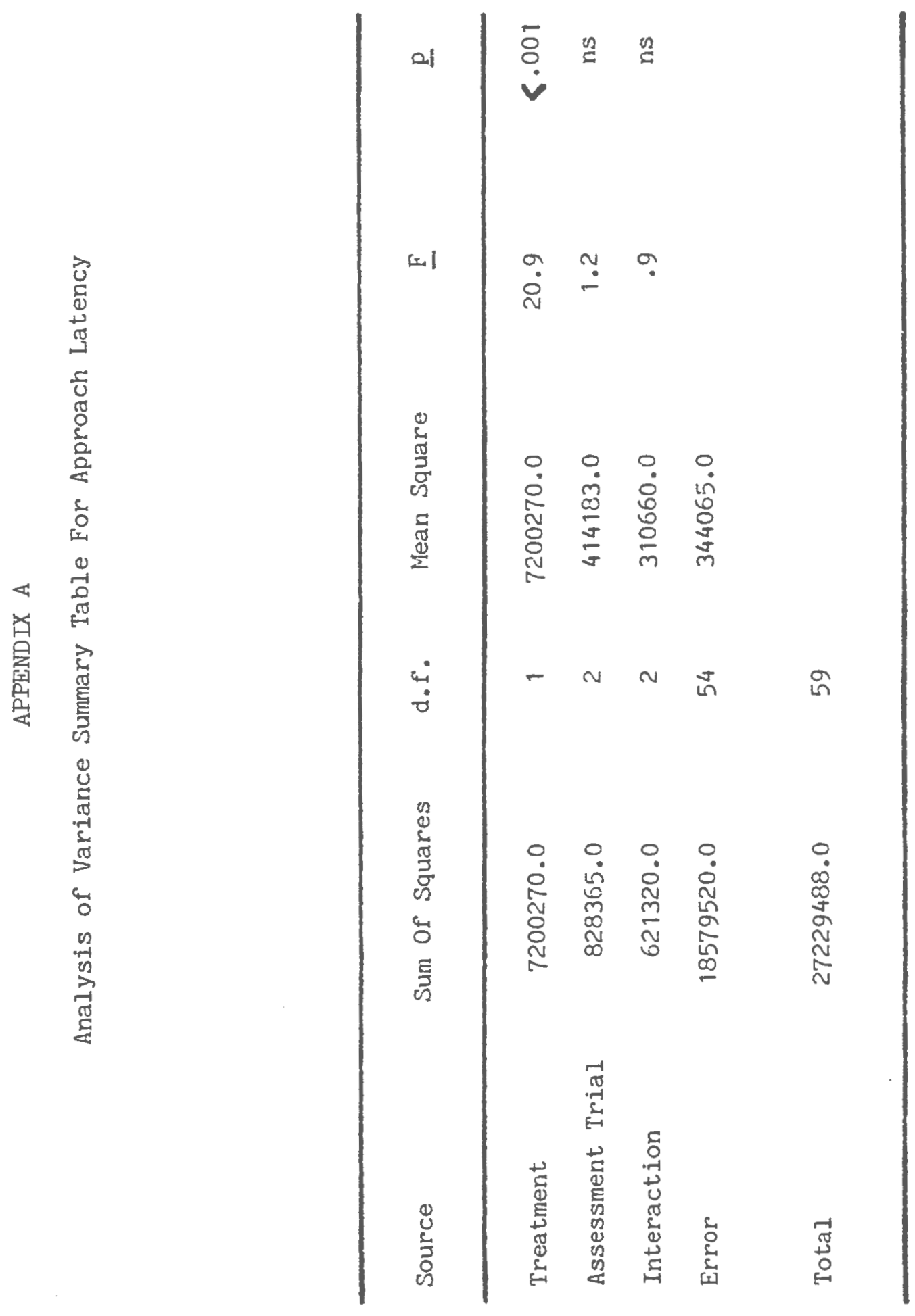


p. 78

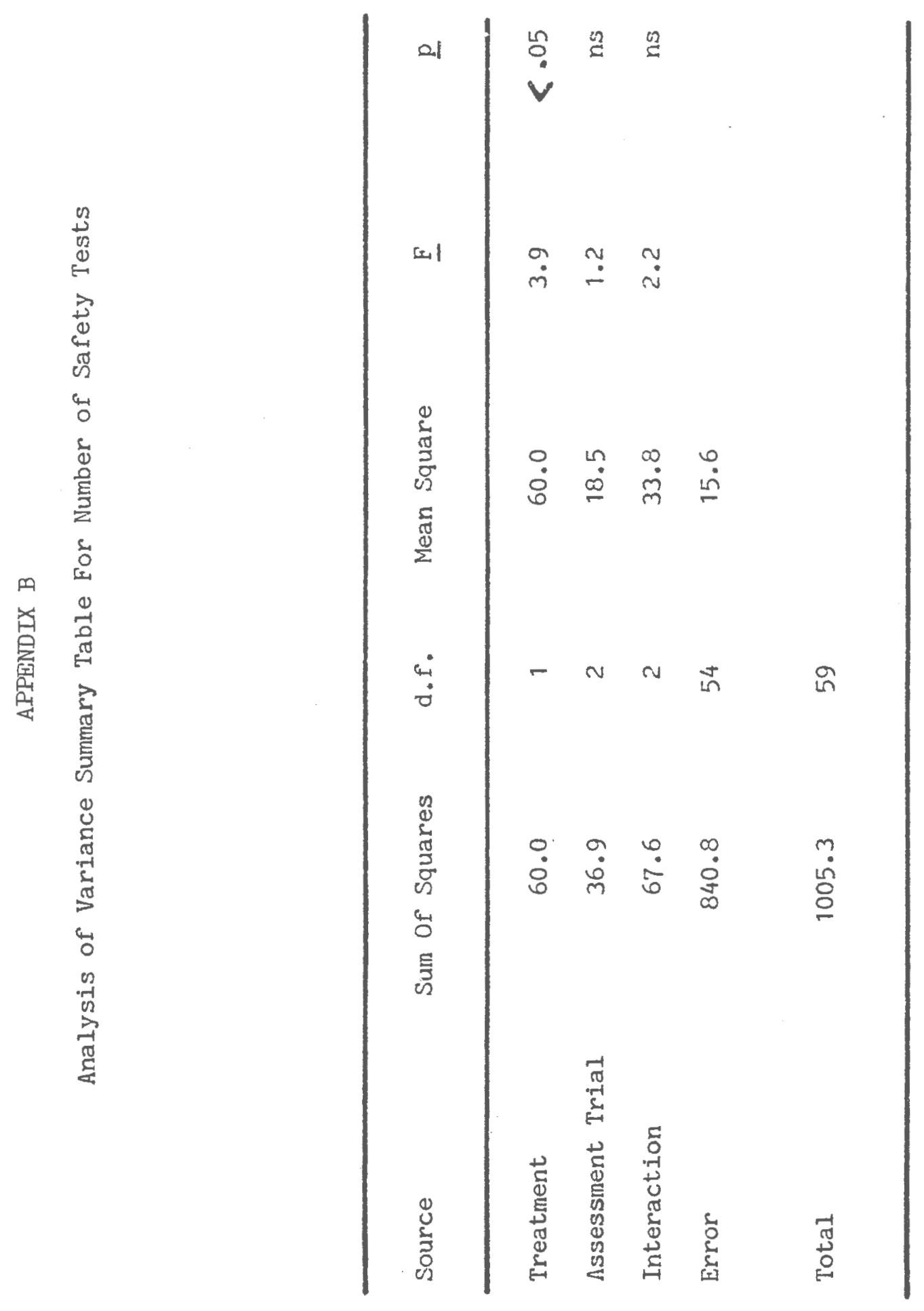


p. 79

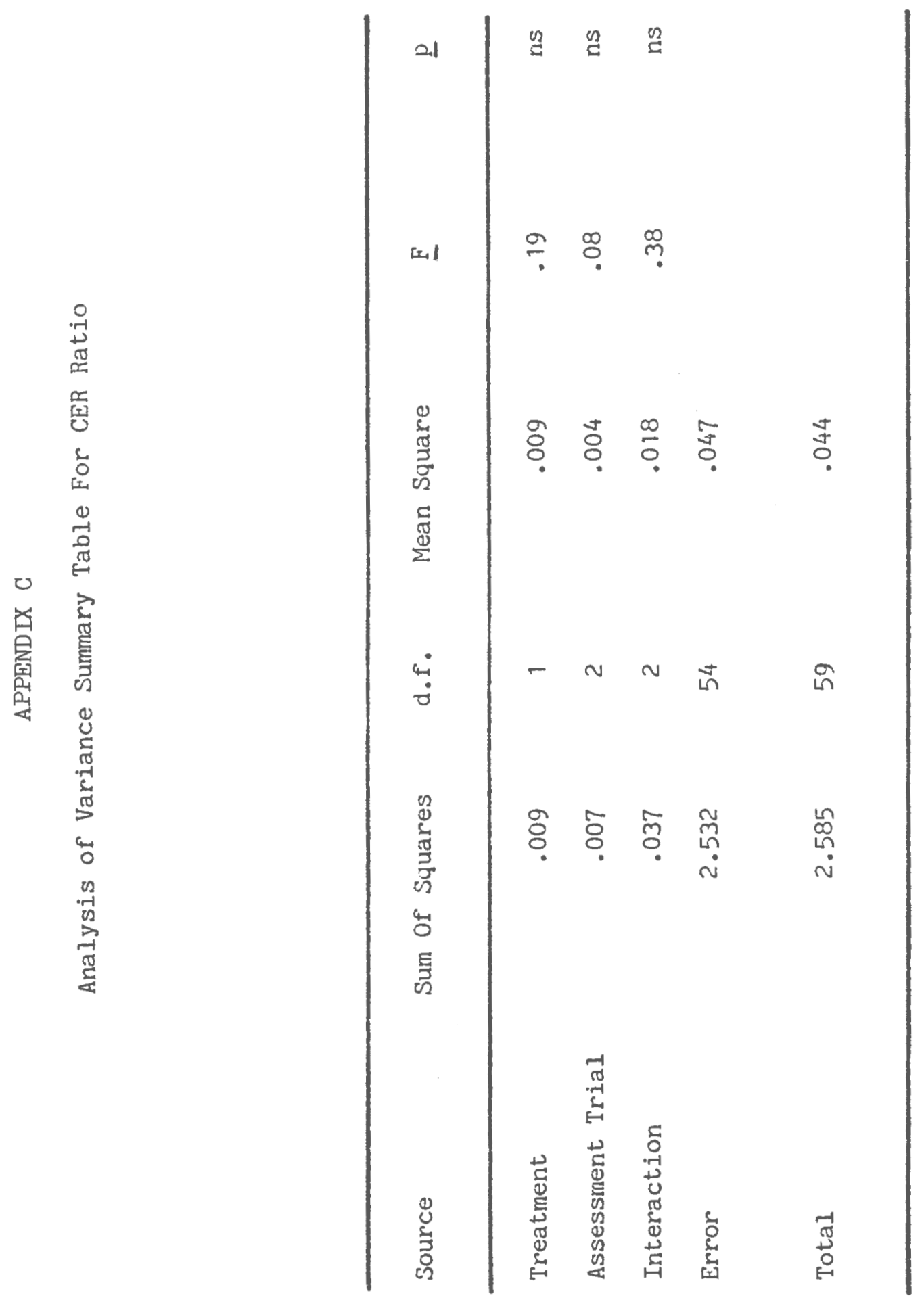


p. 80

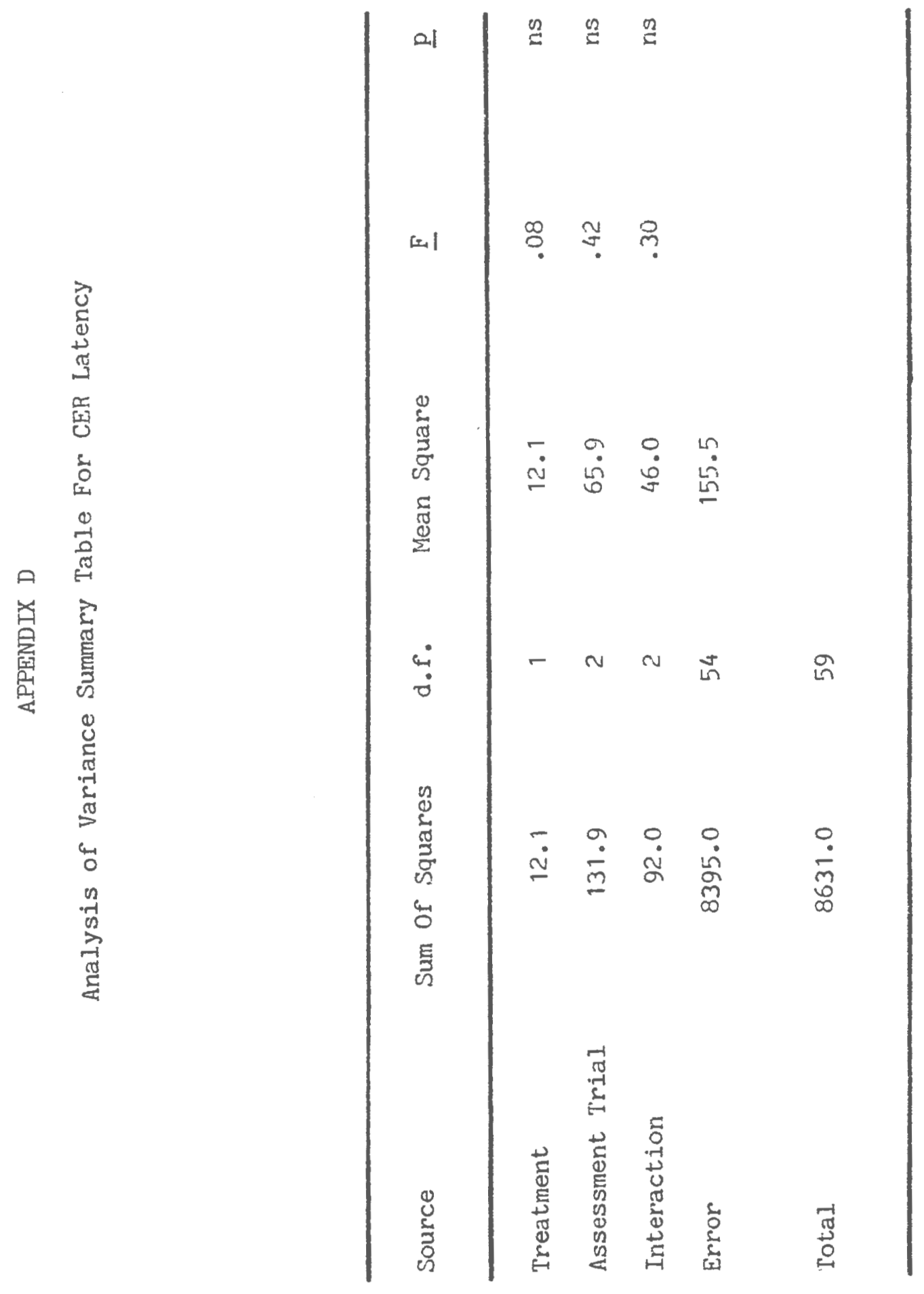


p. 81

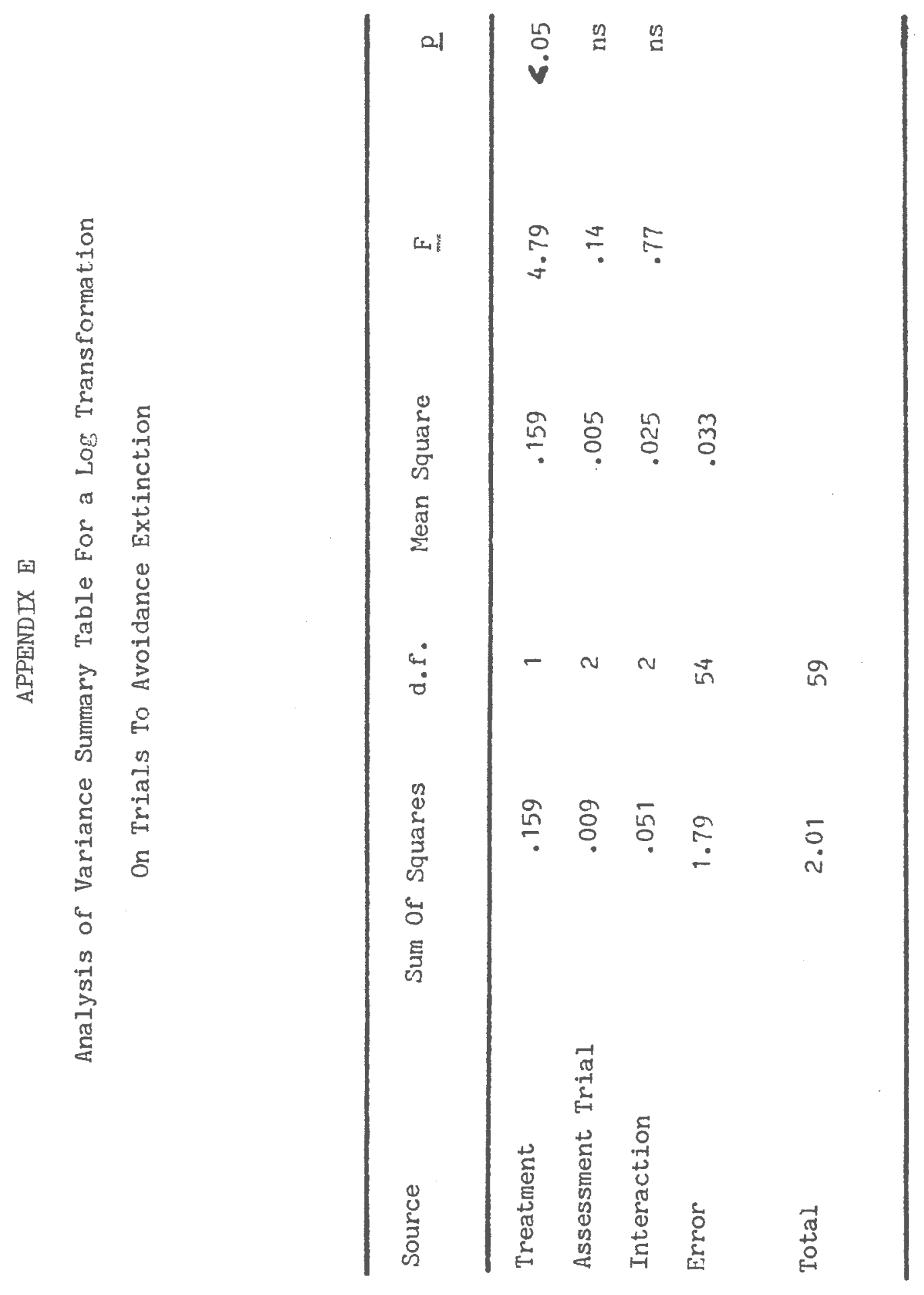


p. 82

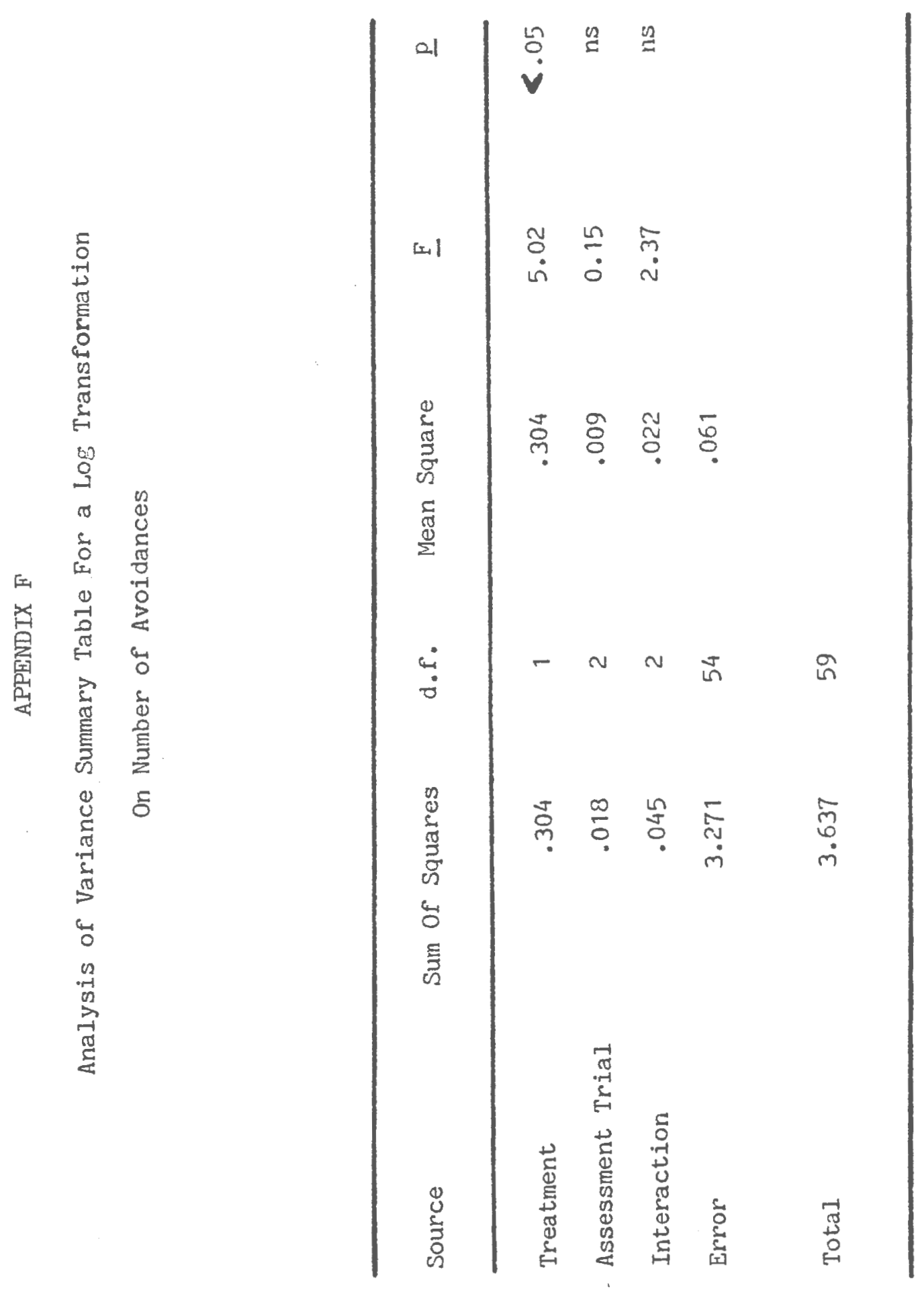




\section{APPENDIX G}

As discussed in the text, this study examined reactivity of measurement by comparing those animals receiving a particular assessment procedure on trial 1 versus those animals receiving the procedure on trial $2 \mathrm{vs.} \mathrm{those} \mathrm{animals} \mathrm{receiving}$ the procedure on the third trial. Those analyses failed to reveal any reactivity of measurement. An alternative strategy presented in this appendix was to examine differences between each of the six potential sequence groups. The analyses of variance performed on all the dependent variables are shown in the following six tables. All these analyses also failed to reveal any significant sequence or interaction effect. 
p. 84

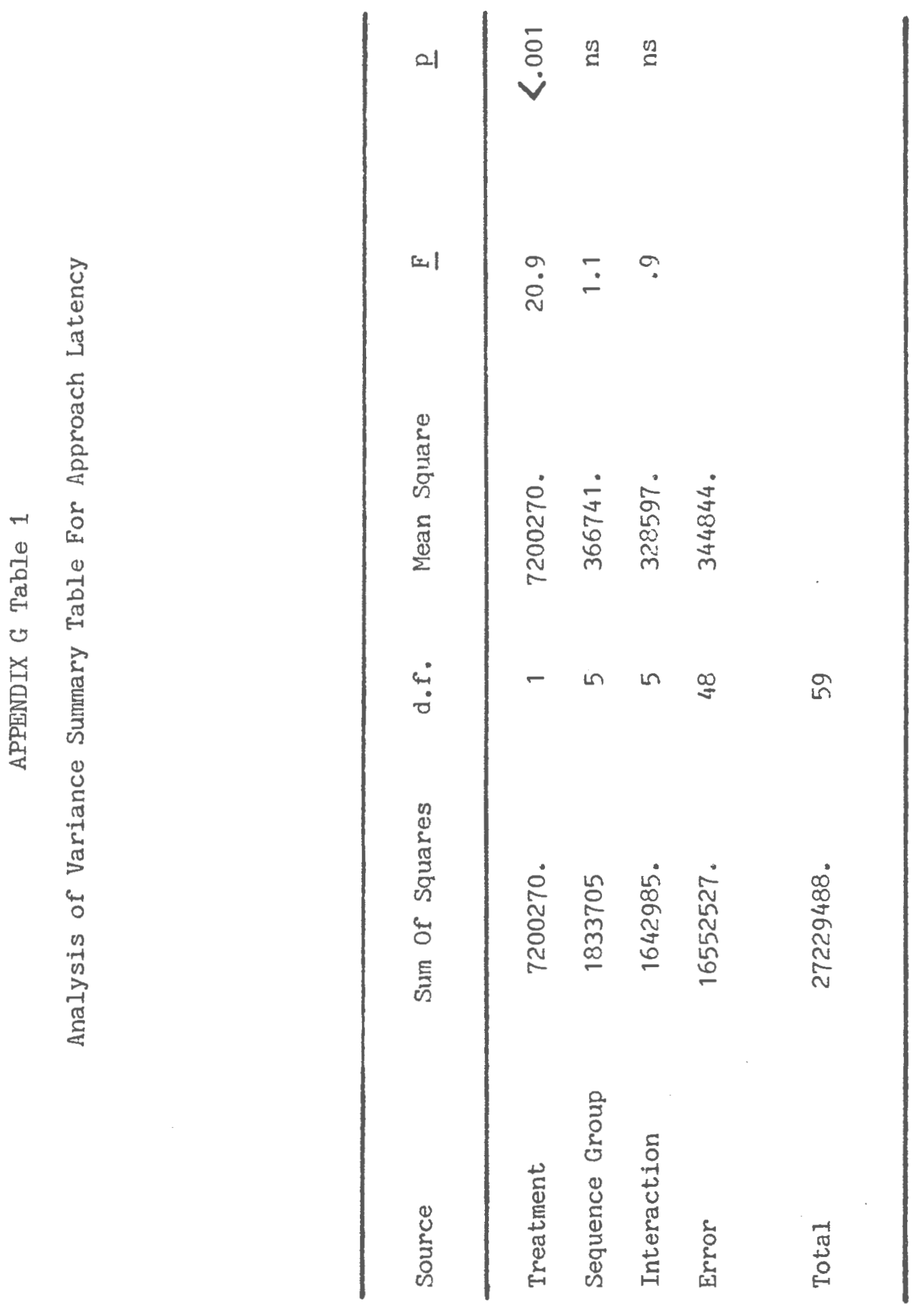


p. 85
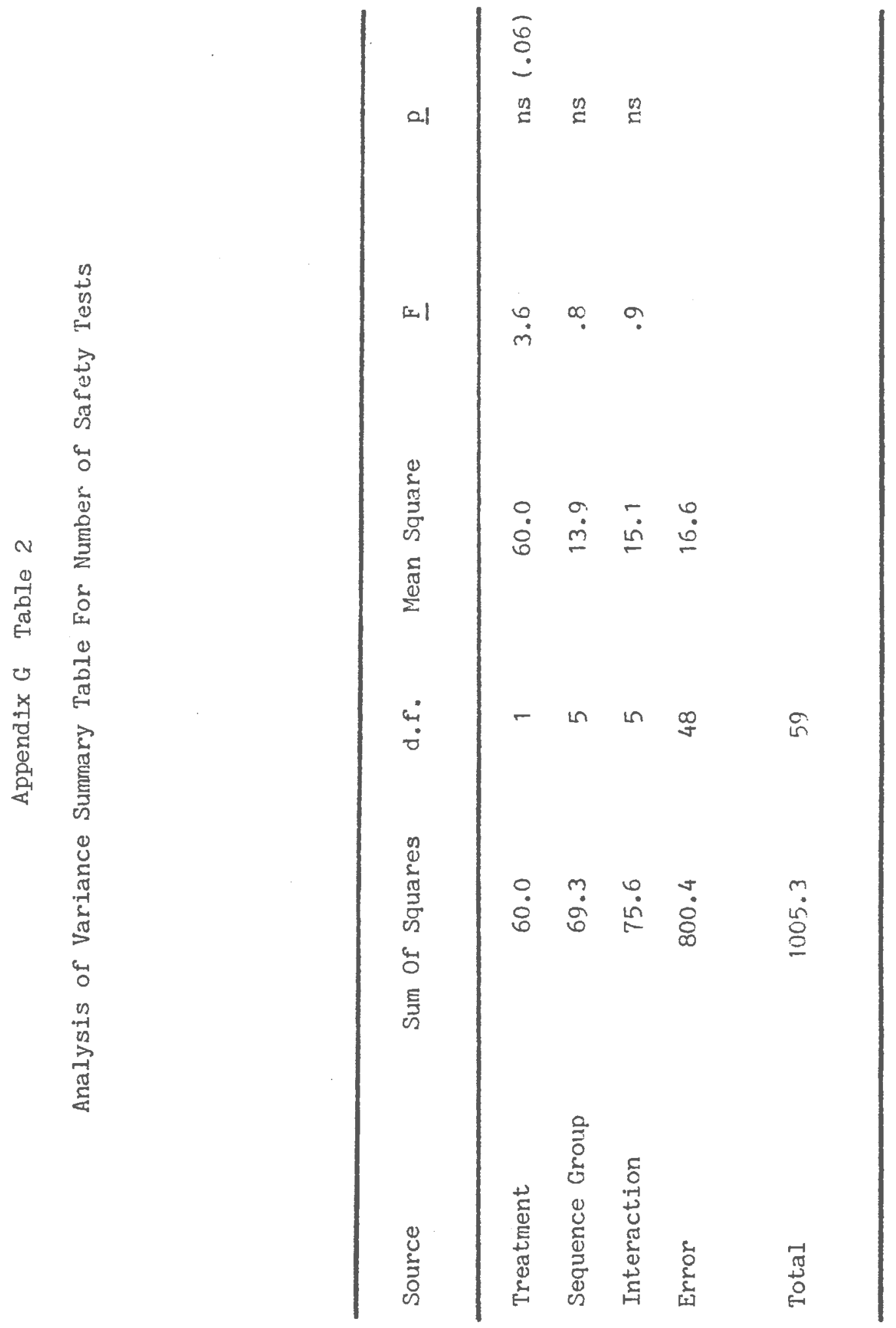

p. 87

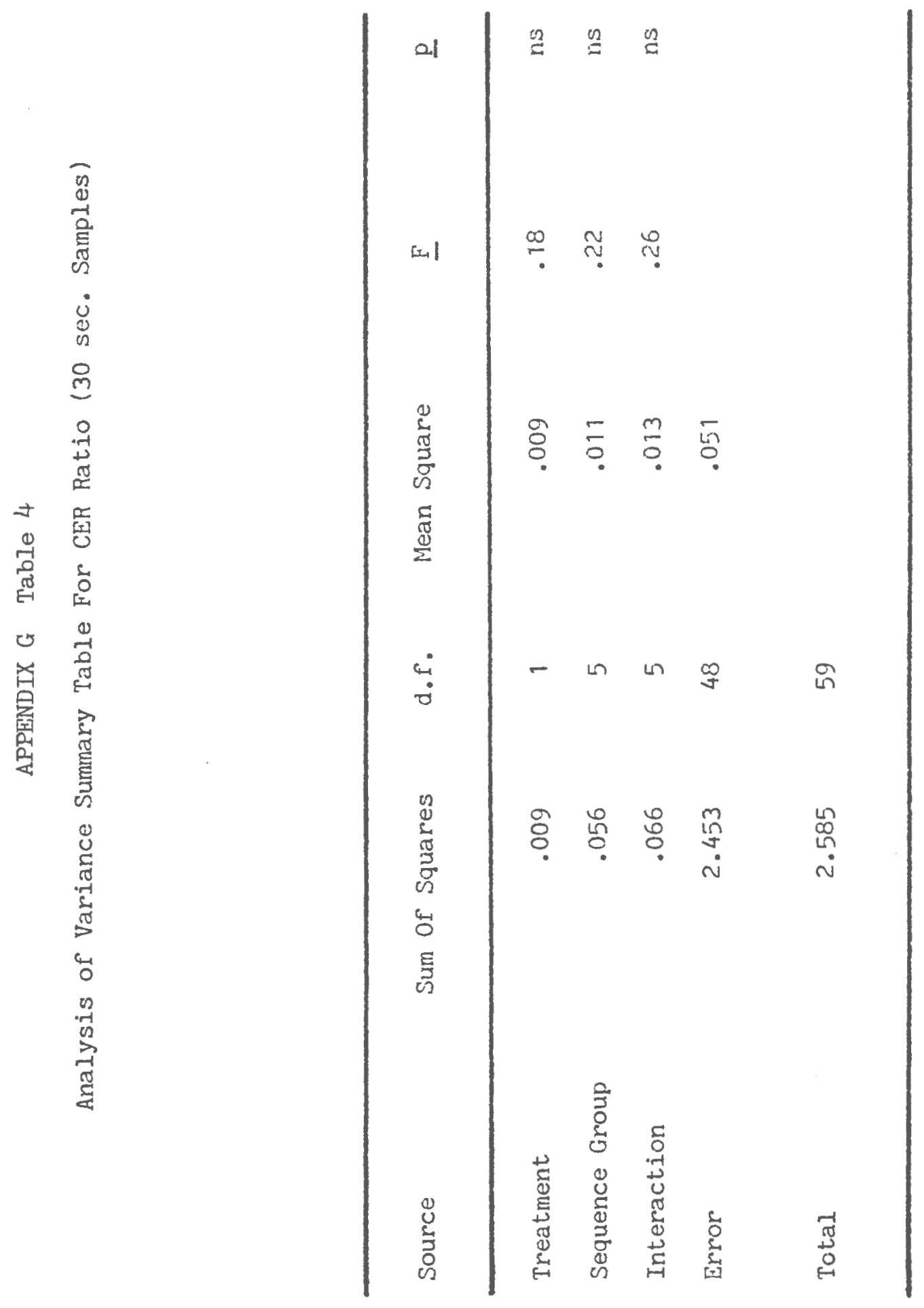


p. 88

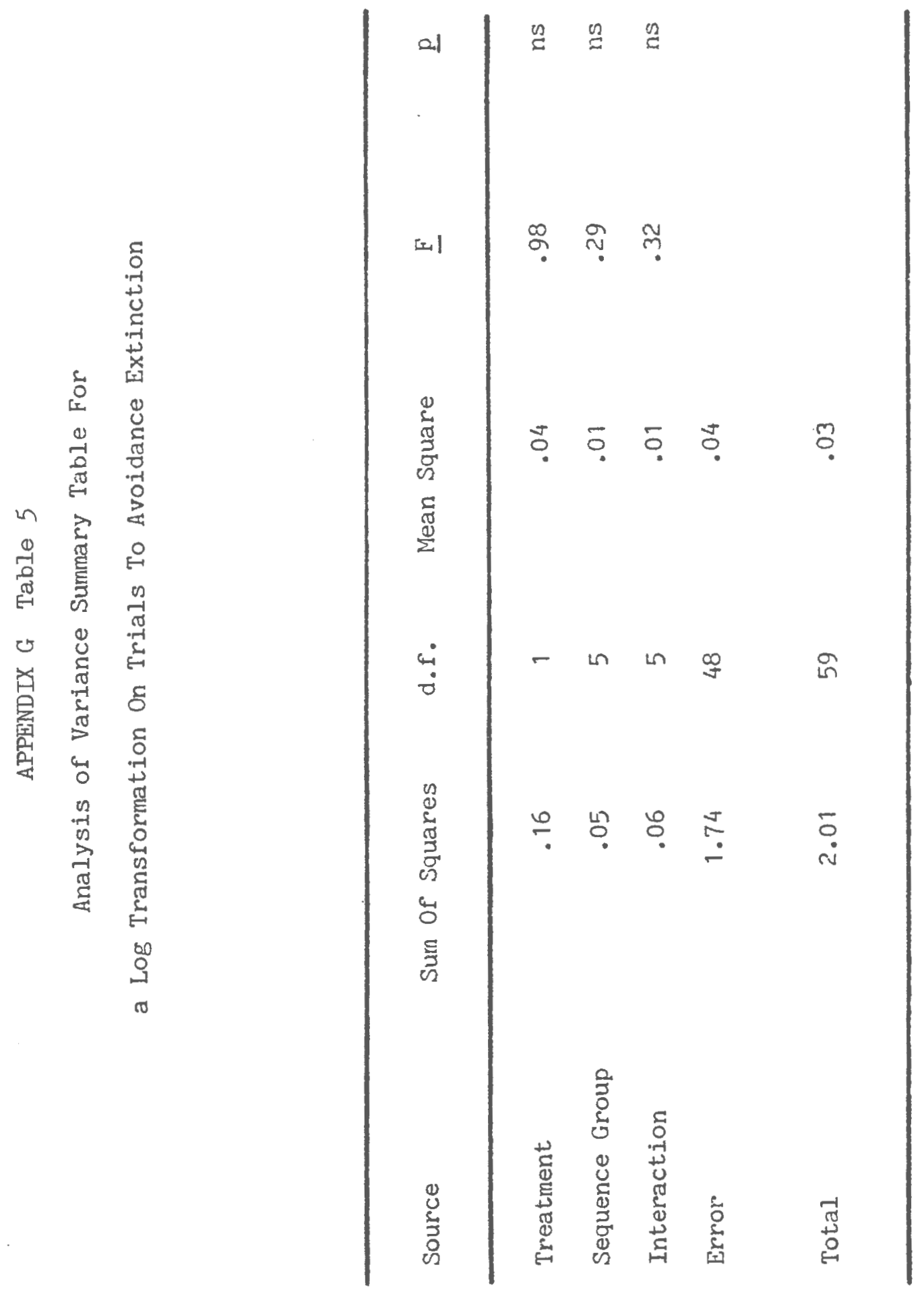


p. 89
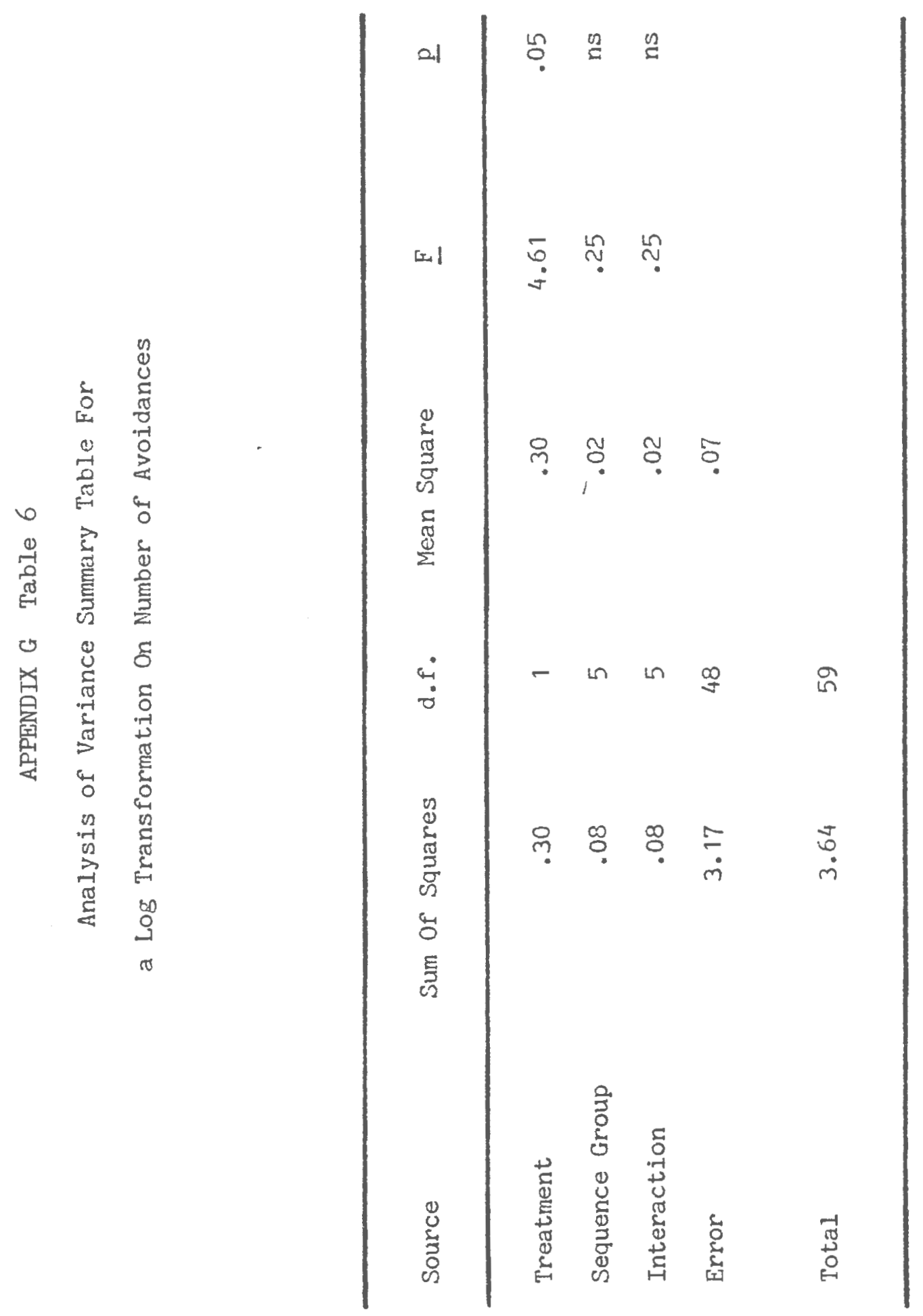